LA- -11971-MS

DE9 1004651

1990 Update for the Applications Guide to Pedestrian SNM Monitors

Paul E. Fehlau 


\section{TABLE OF CONTENTS}

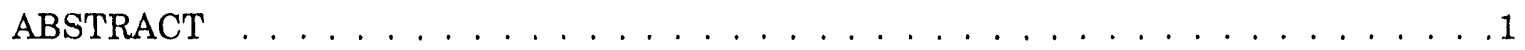

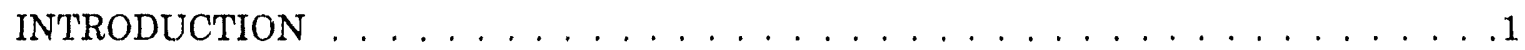

PART 1. 1990 UPDATE TO AN OVERVIEW OF SNM MONITORING . . . . . . . . . . 3

I. PEDESTRIAN SNM MONITORS $\ldots \ldots \ldots \ldots \ldots \ldots$

II. GAMMA-RAY AND NEUTRON MONITORS . . . . . . . . . . . . . . 4

A. Gamma-Ray Monitors . . . . . . . . . . . . . . . . 4

B. Neutron-Detection-Based Monitors . . . . . . . . . . . . . . . 4

III. FACTORS THAT AFFECT PEDESTRIAN SNM MONITOR PERFORMANCE . . .5

A. Nuisance Alarms . . . . . . . . . . . . . . . . . . . 5

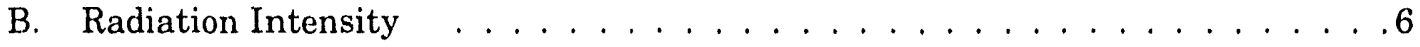

C. Wait-In Monitoring . . . . . . . . . . . . . . . . . .

IV. SNM MONITOR MASS-DETECTION SENSITIVITY $\ldots \ldots \ldots \ldots \ldots$

A. Gamma-Ray Monitor Categories . . . . . . . . . . . . . . . . 8

B. Neutr on Monitor Categories . . . . . . . . . . . . . . . . . .

V. APPLYING AUTOMATIC SNM PEDESTRIAN MONITOR TECHNOLOGY . . . 10

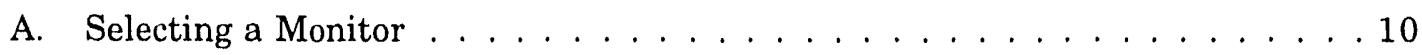

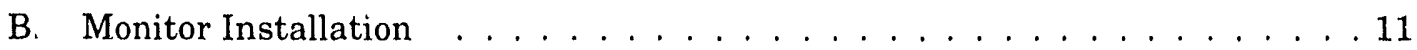

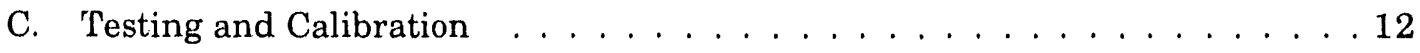

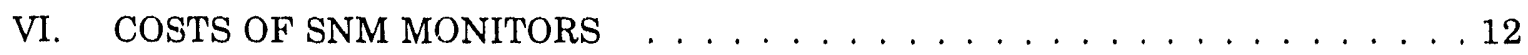

VII. OTHER TYPES OF SNM MONITORS . . . . . . . . . . . . . . . . . . . 12

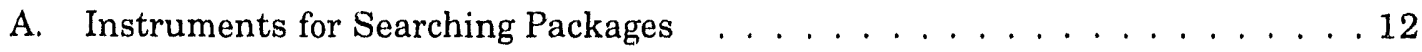

B. Waste-Stream Monitors . . . . . . . . . . . . . . . . . . . . 14

C. Hand-Held Confirmation Instruments . . . . . . . . . . . . . . . 14

PART 2. THE TECHNICAL BASIS OF RADIATION MONITORING . . . . . . . . . 16

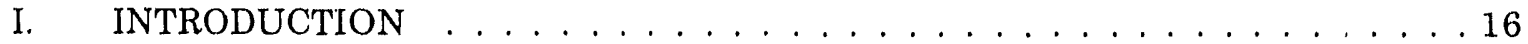

II. PERFORMANCE ASPECTS OF GAMMA-RAY PORTAL DESIGN . . . . . . . . 16

III. THE EFFECT OF DETECTION ALGORITHMS ON PERFORMANCE . . . . . . 17

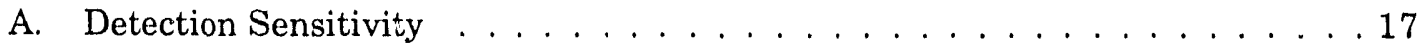

B. Nuisance-Alarm Rate . . . . . . . . . . . . . . . . . . . 18

IV. A DETECTION ALGORITHM FOR PROTRACTED THEFT . . . . . . . . . . . . . 19

V. SNM MONITOR PERFORMANCE EVALUATION . . . . . . . . . . . . . . . 19 
VI. SNM CONFIRMATION INSTRUMENTS . . . . . . . . . . . . . . . . 20

A. Confirmation Measurements . . . . . . . . . . . . . . 20

B. Confirmation Instruments . . . . . . . . . . . . . . . 21

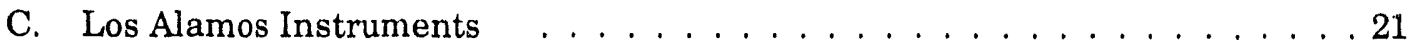

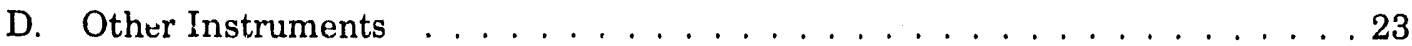

E. Confirmation Measurement Steps . . . . . . . . . . . . . . 24

VII. A BRIEF HISTORY OF NEUTRON PEDESTRIAN MONITORS . . . . . . . . . . 24

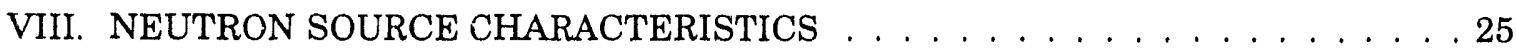

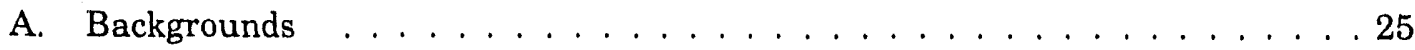

B. SNM Neutron Source Strengths . . . . . . . . . . . . . . . . . 25

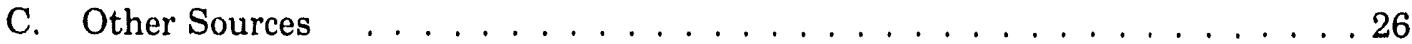

D. Neutron Interactions with Materials . . . . . . . . . . . 26

E. Characteristics of Diversion Signals . . . . . . . . . . . . . . 27

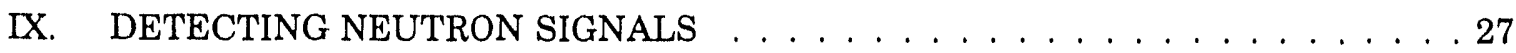

X. NEUTRON DETECTORS FOR NEUTRON-DETECTION-BASED SNM

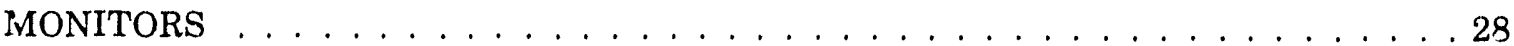

XI. A PROTOTXPE NEUTRON-DETECTION-BASED PEDESTRIAN PORTAL . . . . 29

PART 3. A CATALOG OF PEDESTRIAN SNM MONITORS $\ldots \ldots \ldots$. . . . . . . 31

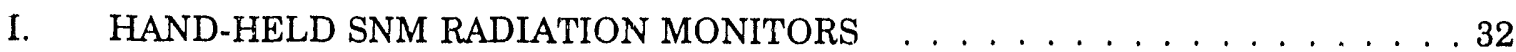

A. TSA Systems, Ltd. HHD-440A . . . . . . . . . . . . . . . . . . 32

B. TSA Systems, Ltd. PRM-470 . . . . . . . . . . . . . . . . 32

C. Jomar Systems, Inc. JHH-20 _ . . . . . . . . . . . . . . . . . . . 32

II. TSA SYSTEMS, LTD., PM-700 SERIES, WALK-THROUGH PORTAL MONITORS 34

III. JOIMAR SYSTEMS MODEL JPM-22 WALK-THROUGH OR WAIT-IN MONITOR 36

IV. CONTAMINATION MONITORS OFFERED FOR USE AS SNM MONITORS . . . 37

V. NEUTRON-DETECTION-BASED PEDESTRIAN MONITOR . . . . . . . . . . 39

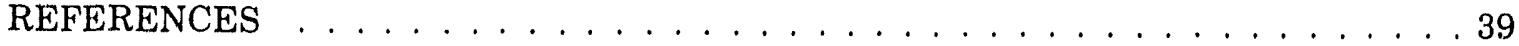

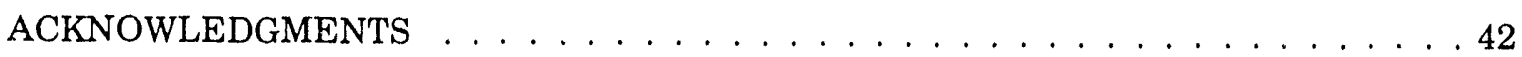

APPENDIX A: A SYNOPSIS OF NUISANCE-ALARM TESTING FROM DRAFT ASTM

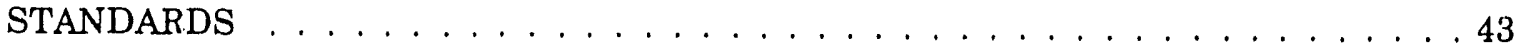

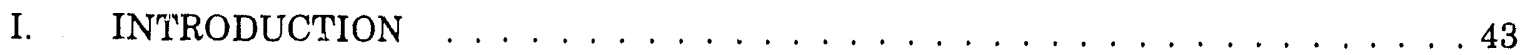

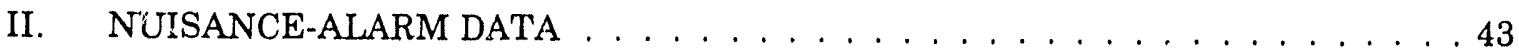

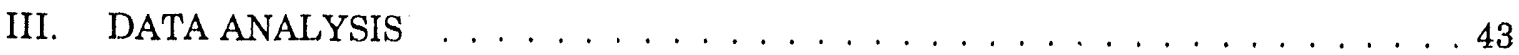

IV. INTERPRETATION OF RESULTS . . . . . . . . . . . . . . . 43 
APPENDIX B: A SYNOPSIS OF TESTING AND CALIBRATION FROM ASTM STANDARDS

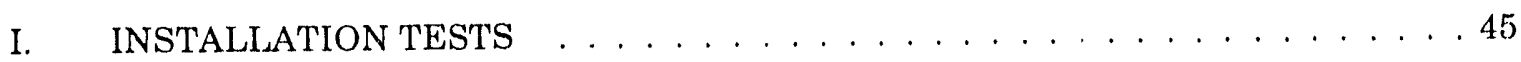

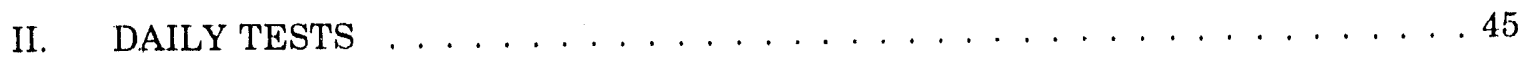

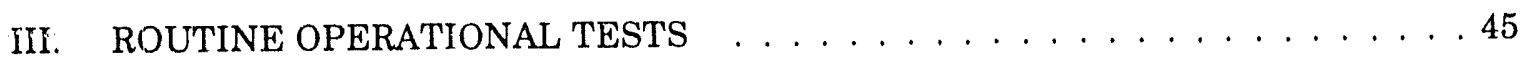

IV. PERIODIC CALIBRATION CHECK AND TESTING . . . . . . . . . . . . . 45 APPENDIX C: A SYNOPSIS ON APPLYING SNM MONITORS FROM ASTM

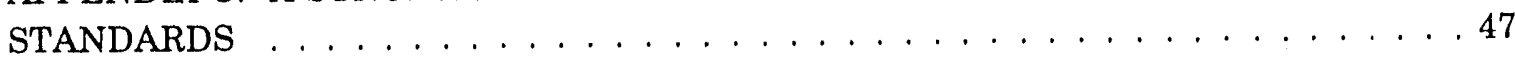

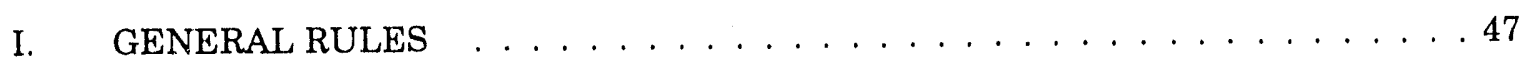

II. BACKGROUND AND OCCUPANCY $\ldots \ldots \ldots \ldots \ldots \ldots \ldots \ldots \ldots$

III. TAMPER RESISTANCE $\ldots \ldots \ldots \ldots \ldots$

IV. BYPASS BARRIERS AND AUDIBLE SIGNALS . . . . . . . . . . 48

APPENDIX D: A SYNOPSIS OF IN-PLANT EVALUATION FROM DRAFT ASTM

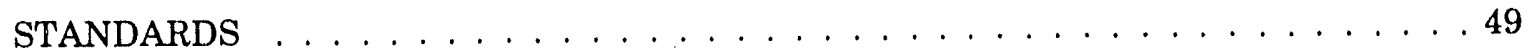



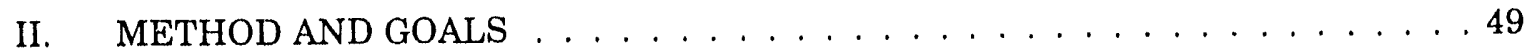

III. MATERIALS AND CRITERIA . . . . . . . . . . . . . 49

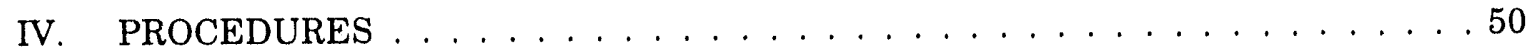

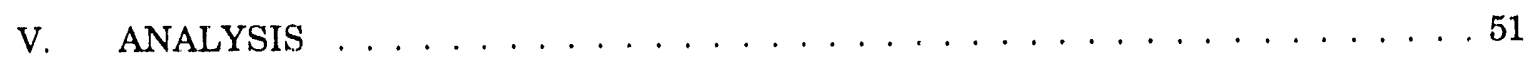

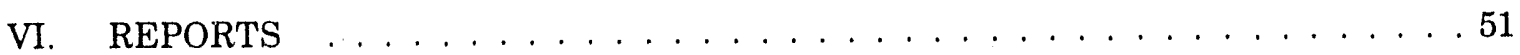




\title{
1990 UPDATE FOR THE APPLICATIONS GUIDE TO PEDESTRIAN SNM MONITORS
}

\author{
by
}

Paul E. Fehlau

\begin{abstract}
The physical principles of special nuclear material (SNM) monitoring have not changed in the five years since the writing of the Los Alamos report, "An Applications Guide to Pedestrian SNM Monitors (LA-10633-MS)." However, during those years, there has been evidence for the start of significant change in the practice of SNM monitoring. Recently revised Dejartment of Energy orders allow flexibility in selecting matcrial-control measures by addressing both abrupt and protracted theft or diversion of SNM and by grading the material according to its attractiveness. Other new guidelines on how to apply, test, and maintain SNM monitors and metal detectors are becoming available from the American Society for Testing and Materials. But perhaps the most noticeable change to the Applications Guide is in Part 3, the catalog of commercial pedestrian SNM monitors, where many obsolete entries have been replaced by new monitors. This update for the Applications Guide catalogs new pedestrian SNM monitors and discusses what is new and what is changing in the practice of SNM monitoring.
\end{abstract}

\section{INTRODUCTION}

The Los Alamos report, "An Applications Guide to Pedestrian SNM Monitors," introduced its readers to pedestrian special nuclear material (SNM) monitors, which are one of the means that the Department of
Energy (DOE) and its contractors use for nuclear material control. The Applications Guide explained how the monitors operate, how they can be applied, and how they can be calibrated and maintained. The Guide was divided into three parts: an overview of pedestrian SNM monitoring in Part 1; 
technical discussions in Part 2; and a catalog of pedestrian SNM monitors in Part 3. This report updates the Guide by discussing the significant changes to the practice of SNM monitoring that have taken place in the 5 years since it was written. The update also discusses other topics that time has shown were not adequately presented or emphasized in the original Guide.

The purpose of this update is the same as that for the previous report ${ }^{*}$ : to present a wide variety of material to an audience of adminisirators, security specialists, and technicians in a manner that lets each of them locate pertinent information easily. As in the Guide, the update is divided into parts that serve different purposes. Part 1 is an overview and introduces information on new aspects of applying and maintaining SNM monitors and may have the most general audience. Part 2 is more technical and discusses performance aspects of gamma-ray and neutron monitors, confirmation instruments, and the history and physics of neutron monitors. Part 3 catalogs new commercially available pedestrian SNM monitors and quotes comparative evaluation information when available.

* Readers who would like a copy of the original Guide can request one from the author at FTS 843-5372 or commercial (505) 667-5372. 


\section{PART 1 \\ 1990 UPDATE TO AN OVRRVIEW OF SNM MONITORING}

\section{PEDESTRLAN SNM MONITORS}

Both hand-held and automatic SNM monitors continue to be used for monitoring pedestrians for concealed SNM as they leave material access areas (MAAs) and some protected areas (PAs). The ability of the monitors to sense gamma rays and neutrons emitted by the SNM still offers the most convenient and effective way of searching pedestrians for SNM. New SNM portal monitors that use the conventional plastic scintillation detectors have become available, and new portal monitors that are based on detecting only neutrons are becoming commercially available. In addition, new hand-held instruments are now available for manually searching pedestrians for SNM, and new hand-held confirmation instruments are available for confirming that radioactive material detected in a monitor either is or is not SNM. This Part introduces new information that, in many cases, is further discussed in Part 2 and may be represented in the new monitors cataloged in Part 3.

The DOE orders regulating nuclear safeguards and security continue to call for a physical or electronic search for SNM at routine exit points from MAis and PAs. However, the material-control and accountability order is now more performance related and facility oriented. It calls for detecting shielded SNM, but the SNM is to be typical SNM product material. These and other new factors in the DOE order, such as material attractiveness and the need for other types of monitoring, are discussed in Secs. III.B and VII.

Routinely checking SNM monitor performance remains an important part of keeping SNM monitors operating properly. The American Society for Testing and Materials (ASTM) is developing and issuing guides for evaluating the performance of perimeter security devices. These guides are consensus documents being developed by ASTM subcommittee C26.12 on Safeguards Applications, which is composed of volunteers" from regulatory agencies, DOE contractor facilities, and equipment manufacturers. The subcommittee has published ${ }^{2}$ its first guide, the "Standard Guide for Application of Radiation Monitors to the Control and Physical Security of Special Nuclear Material" (C1112-88), which provides an overview of SNM monitors, and how they can be applied,

* Interested volunteers should contact the ASTM C26.12 staff manager at (215) 299-5529 for further information.

*** Available from the American Society for Testing and Materials, 1916 Race St., Philadelphia, PA 19103 at a cost of $\$ 8.00$. 
maintained, and tested. Other subcommittee work in progress on evaluating SNM monitor performance will be discussed in Part 1, Sec. V.C and Sec. V of Part 2. The subcommittee is also beginning to develop guides for evaluating the performance of metal detectors.

\section{GAMMA-RAY AND NEUTRON MONITORS}

\section{A. Gamma-Ray Monitors}

When the Guide was written, gamma-ray monitors were the only commercially available type of SNM monitor. Many of these monitors used plastic scintillators, which also detect energetic neutrons emitted by some types and forms of SNM. Gamma-ray monitors continue to be the only way to sense the presence of SNM that does not emit a significant number of neutrons, metallic uranium for example.

Some forms of uranium do emit a few neutrons, but the most intense neutron emitter, highly enriched $\mathrm{UF}_{6}$, emits only about $5 \%$ of the number emitted by the same mass of metallic, low-burnup plutonium. Hence, gamma-ray monitors will always be very import ant for detecting highly enriched uranium (HEU). However, uranium gamma rays are relatively easily shielded, and metal detectors may be needed to detect uranium shielded by a metallic material.

Gamma-ray monitors are also very effective for detecting plutonium, which emits both energetic neutrons and many more gamma rays than an equal amount of uranium. The neutions and some of the gamina rays emitted by plutonium are penetrating and difficult to shield. Monitors using plastic scintillators readily detect the penetrating gamma rays and neutrons, making metal-shielding detectors unnecessary in many cases.

\section{B. Neutron-Detection-Based Monitors}

Part 1 of the Applications Guide briefly mentioned work in progress on neutrondetecting monitors that were being developed for monitoring vehicles for plutonium. Since then, both pedestrian and vehic'e, neutrondetection-based, plutonium monitors have been developed and evaluated. After being evaluated in laboratory and plant environments, these monitors are now becoming commercially available. The significant difference between neutrondetection-based monitors and gamma-ray monitors is that the ability of gamma-ray monitors to detect very small quantities of plutonium is lost when the plutonium is shielded; whereas the ability of neutron monitors to detect shielded plutonium is quite good. The neutron-detection-based monitors may detec $\$$, only tens of grams of bare plutonium rather than fractions of a gram, but when the plutonium is enclosed in shielding material, in some cases the neutron monitors may deiect even smaller quantities of plutonium. The reason for this is that shielding materials may provide neutron moderation that improves the sensitivity of a neutron-detection-based monitor.

Two factors make neutron-detection-based portals more effective for detecting shielded plutonium: (1) neutron portals sense only neutrons, which usually have very low background intensity; and (2) they can use undermoderated, thermal neutron detectors that may have increased sensitivity when plutonium is shielded. The first factor (low background) allows neutron portals to detect weak neutron signals that are below the detection threshold in other monitors. For example, the detecticn threshold of a plasticscintillator portal i.s higher because its background stems principally from gamma-rays, which are much more intense in 
background than neutrons. The second factor (undermoderation) allows detecting even weaker signals when neutron shielding materials up to $4 \mathrm{~cm}$ thick are placed around plutonium. The shielding material provides additional moderation of plutonium neutrons, which makes them more detectable in the undermoderated detector.

Figure 1 illustrates the two types of neutron-detection-based monitor. Pedestrian, neutron-detection-based monitors are discussed further in I'arts 2 and 3.

(a)

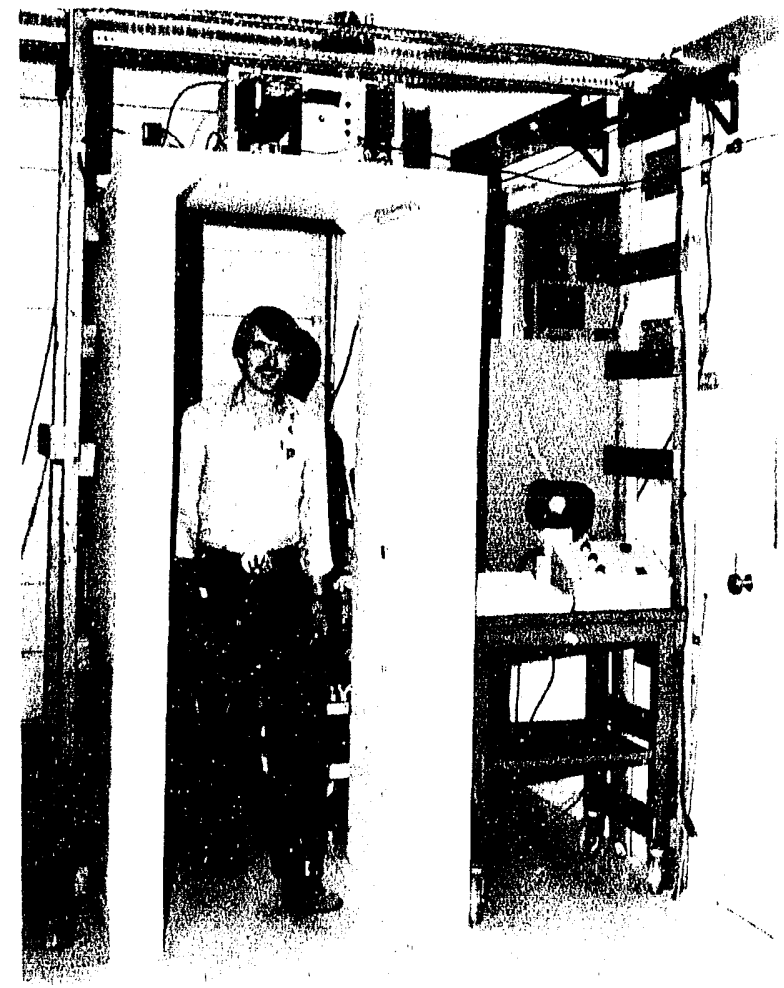

\section{FAC'TORS 'THA'T' AFFECT PEDESTRIAN SNM MONITOR PERFORMANCE}

\section{A. Nuisance Alarms}

A monitor's detection sensitivity and nuisance alarm rate (from counting statistics and background variation) are closely related. An increase in detection sensitivity by lowering the alarm threshold will also increase nuisance alarms. Note that sensitivity should not be obtained at the sacrifice of a low nuisance alarm rate. Doing so could cause an excess of (b)

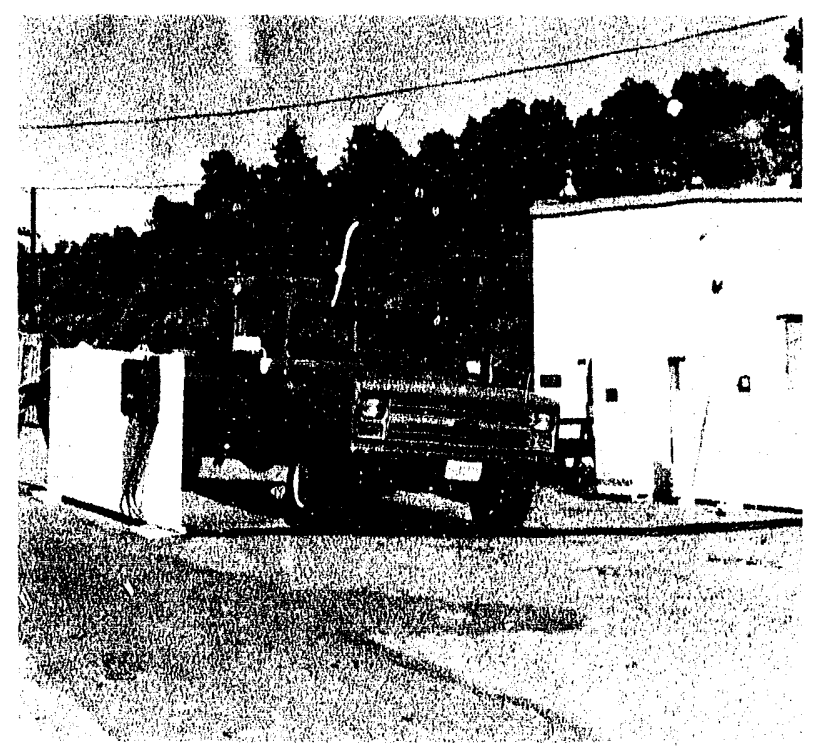

Fig. 1. The prototype neutron detection-based portals for pedestrians (a) and vehicles (b) have been evaluated in production plants and are now becoming commercially available. 
nuisance alarms that reduces the monitor's credibility and prevents proper alarm resolution. Operating records should be examined to ensure that a monitor's nuisance-alarm rate is not excessive. Information on nuisance alarms and number of passages can be hand written in a station log. Automatic recording is also possible in some monitors. The ASTM draft "Standard Guide to In-Plant Performance Evaluation of Automatic Pedestrian SNM Monitors," summarized in Appendix A, recommends examining the nuisance-alarm record as part of in-plant performance testing. The appendix shows how to determine an average number of nuisance alarms per passage and reviews information on published guidelines for acceptable rates. Knowing the monitor's nuisance-alarm rate per passage and the average number of passages per day or work shift may help you to decide whether a security inspector's judgment in resolving alarms could be biased by frequent nuisance alarms.

Unnecessary nuisance alarms from misoperation can be avoided by keeping a monitor in good repair through a maintenance program that includes periodic testing and recalibration. Appendix B summarizes the ASTM recommendations for calibration and testing frequency. Unnecessary nuisance alarms from other causes may also be possible to avoid. For example, situating a monitor where it is well isolated from process areas can reduce nuisance alarms from varying backgrounds.

\section{B. Radiation Intunsity}

The intensity of the signal being detected is an important factor in any kind of monitoring. The Applications Guide mentions that selfabsorption of radiation within a material diminishes its emitted radiation intensity. For comparative laboratory evaluations, the Guide establishes pedestrian monitor performance categories for detecting materials having maximum self-absorption (worst-case forms of material). For operational performance evaluation, the new DOE material-control and accountability Order 5633.3 calls for using SNM in the form of process materials. Similarly, the new ASTM guides call for using agreeable (between facility and regulator) test sources (which can be process material) for in-plant evaluation. The process materials will often have much loss self-absorption and emit more radiation than equal masses of the worst-case forms of SNM. Table I illustrates the difference between self-absorption in process materials and standard metallic test sources. The self-absorption factor for a 10.7-g sphere of uranium material decreases by about a factor of 3 between solid metallic material and oxide powder; hence, process materials can emit up to three times as much radiation per gram of uranium, making them easier to detect when they are unshielded.

Although, the amount of self-absorption may be less important in detecting shielded SNM, equal masses of lower density, metallicshielded, process materials should be much more easily detected in metal detectors because of increased size. The lower the density of a particular mass of process material, the larger will be its volume and the size of the shielding material required. A further doubling in mass (and volume) takes place under DOE Order 5633.3 if the materials have a level-C attractiveness, as is the case for the oxides. Table II illustrates the relative weight and surface area of metallic lead shields that might be required for the $\mathrm{m}^{\prime}{ }^{+}$erials in Table I to shield attractiveness level $\mathrm{B}$ and $\mathrm{C}$ material during protracted theft. Both the mass and the surface area, a factor that can affect metal detector performance, are greatly increased as the density decreases. The shields may need to be as mu ' $h$ as a factor of 5 


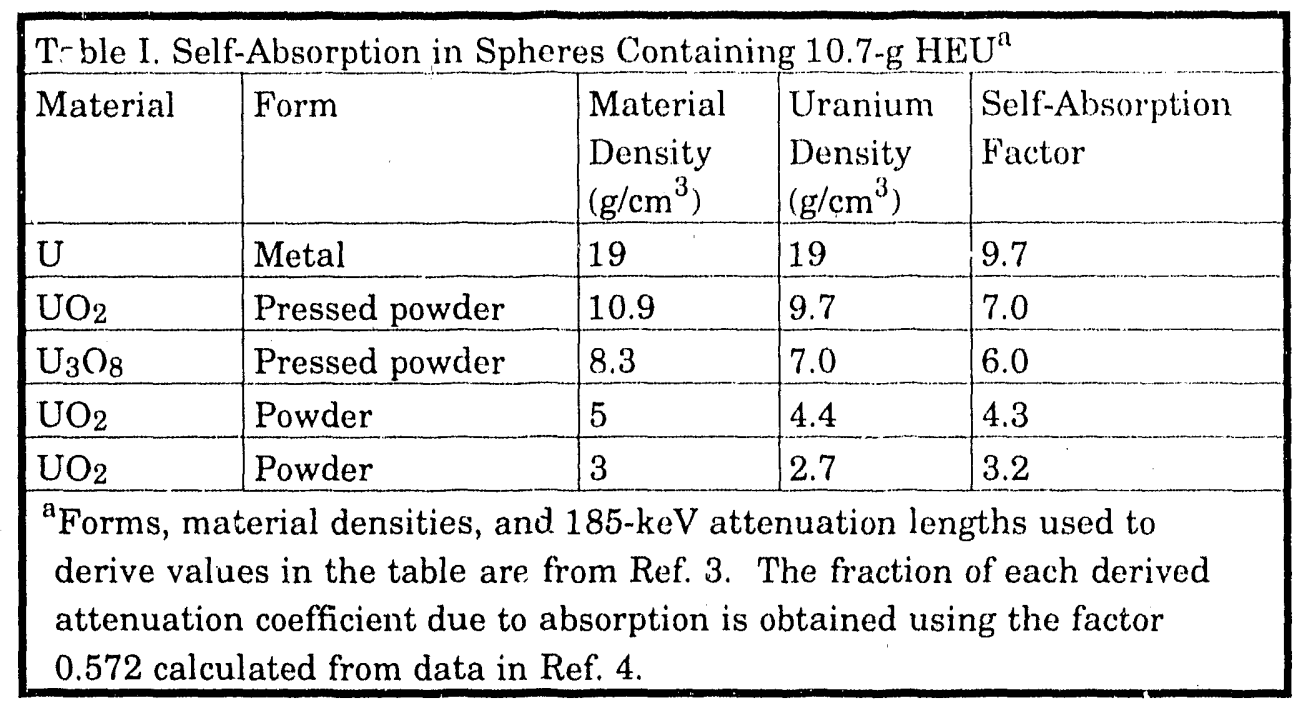

Table II. Relative Shield Mass and Surface Area for Different HEU Density and Attractiveness ${ }^{\mathrm{a}}$

\begin{tabular}{|l|l|l|l|l|}
\hline \multirow{2}{*}{ Material } & Form & $\begin{array}{l}\text { Attractiveness } \\
\text { Level }\end{array}$ & Relative \\
\cline { 3 - 5 } & & Mass & Surface Area \\
\hline $\mathrm{U}$ & Metal & B & 1 & 1 \\
\hline $\mathrm{UO}_{2}$ & Pressed powder & $\mathrm{C}$ & 2.3 & 2.2 \\
\hline $\mathrm{U}_{3} \mathrm{O}_{8}$ & Pressed powder & $\mathrm{C}$ & 2.8 & 2.6 \\
\hline $\mathrm{UO}_{2}$ & Powder & $\mathrm{C}$ & 3.7 & 3.4 \\
\hline $\mathrm{UO}_{2}$ & Powder & $\mathrm{C}$ & 5.1 & 4.7 \\
\hline $\begin{array}{l}\text { a Based on a lead shielding thickness to reduce the detection probability of a } \\
\text { formula quantity to } 50 \% .\end{array}$
\end{tabular}

larger in mass or surface area than the shields used for the same mass of metal. If only the larger shields need to be detected, metal detectors can be more effective and possibly operate at a sensitivity level that is more tolerant of innocent items carried by pedestrians.

The increased detectability of an equal mass of bare or shielded low-density process materials also can be found in some fabricated items. Geometric forms that have a larger surface area for their mass than compact solids have increased detectability on an equal mass basis. Low-density uranium-aluminum alloys used in fuels also have increased detectability from their low uranium density. As a result, uranium materials in the form of flat fuel piates or hollow shapes are more readily detected in SNM monitors and would require larger quantities of a metallic shielding material that could be more readily detected by metal detectors.

\section{Wait-In Monitoring}

The Applications Guide mentions that longer monitoring times can improve monitoring sensitivity and gives one example of a wait-in monitor in its catalog. Routine use of wait-in monitors has recently begun. Figure 2 illustrates a pedestrian SNM 


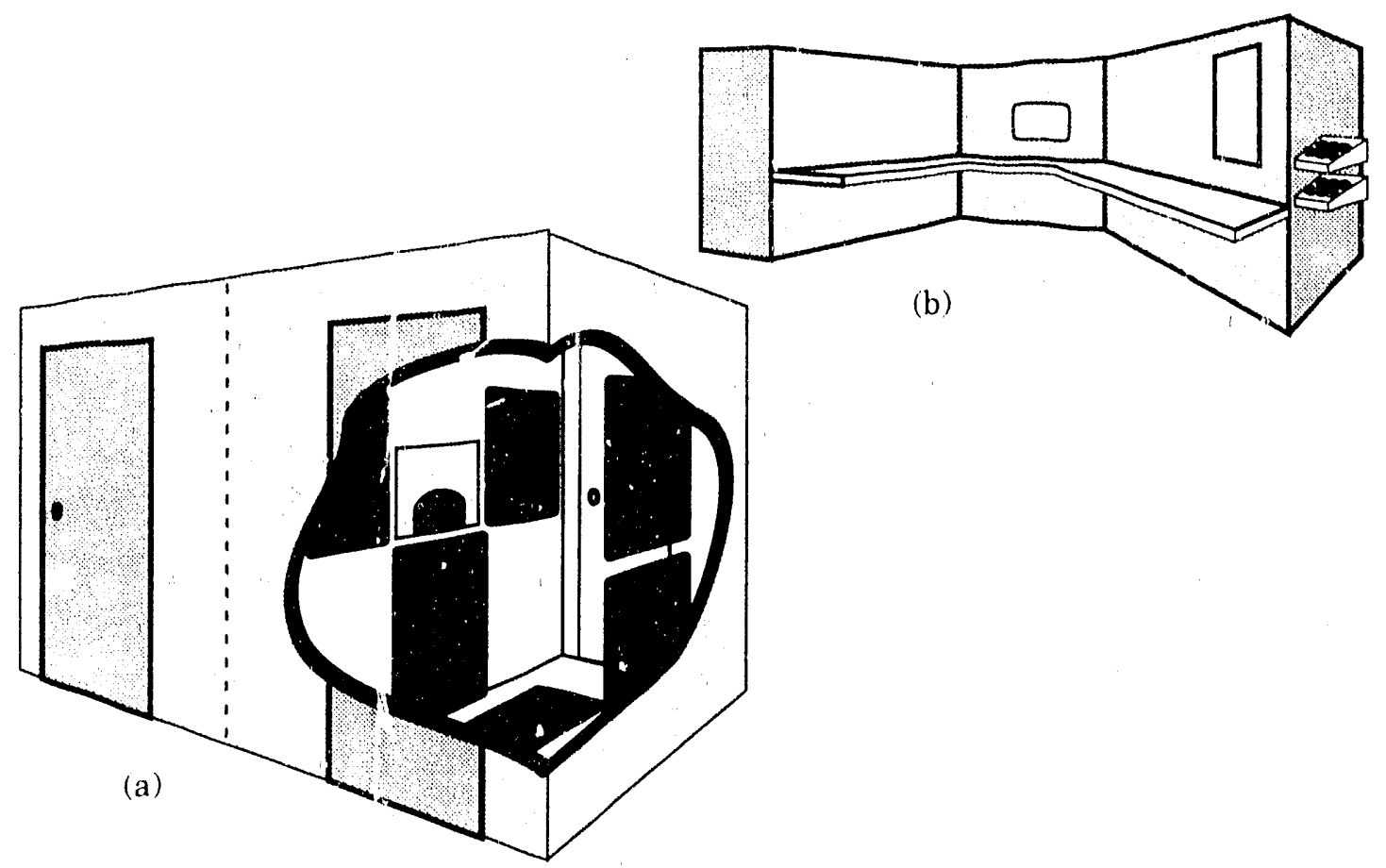

Fig. 2. Artist's conception of SNM monitoring booths (a) at Sandia National Laboratories, which were developed by Sandia in cooperation with Los Alamos. Activity in a monitoring booth is supervised by a security inspector at the console (b).

monitoring station with two outgoing lanes inst)umented for SNM monitoring. The radiation detectors are in a booth where pedestrian crederitials are examined for exit approval. The detectors are positioned in front and behind the pedestrian as well as under his feet. During monitoring, the pedestrian can be observed from above on a television screen. The pedestrian's face is imaged separately and compared to the badge image. The catalog in Part 3 describes the basic Jomar JPM- $22^{*}$ pedestrian monitor used in the station as well as in walk-through monitors that also have optional wait-in capability.

\section{SNM MONITOR MASS-DETECTION SENSITIVITY}

\section{A. Gamma-Ray Monitor Categories}

Mass-detection-sensitivity categories for walk-through SNM monitors that weri introduced in the Applications Guide are listed in Table III. The sensitivity categories are used to compare the pe:formance of pedestrian monitors in laboratory evaluations that take place under a set of worst-case conditions and with worst-case materials as test sources. Many Category I or II monitors have been evaluated and are readily available. Several Category III monitors have been evaluated, but

* Jomar Systerns, Inc., 110 Eastgate Dr., Los Alamos, NM 87544 (505) 662-9811. 


\begin{tabular}{|c|c|c|c|}
\hline Category & Description & Uranium $^{\mathrm{b}}(\mathrm{g})$ & Plutonium ${ }^{\mathrm{c}}(\mathrm{g})$ \\
\hline$I$ & Standard plutonium & 64 & 1 \\
\hline II & Standard uranium & 10 & 0.29 \\
\hline III & Improved Sensitivity & 3 & 0.08 \\
\hline IV & High Sensitivity & 1 & 0.03 \\
\hline \multicolumn{4}{|c|}{$\begin{array}{l}{ }^{\mathrm{a}} \text { In a nominal } 20-\mu \mathrm{R} / \mathrm{h} \text { background intensity using standard metallic } \\
\text { test sources and procedures. } \\
{ }^{\mathrm{b}} \mathrm{HEU} \text {. } \\
\text { c Low-hurnup plutonium. }\end{array}$} \\
\hline
\end{tabular}

these have usually beer wa t-in rather than walk-through monitors. No monitor has yet achieved Category IV performance in an evaluation, even as a wait-in monitor.

The basic differences between monitors (other than performance) in the different categories was not discussed in the Guide. Some aspects of a monitor's basic design are characteristic of its performance category. The most common walk-through portal monitors are Category II monitors, which are a convenient point of reference for discussing monitor categories. Category II monitors have modest-size radiation detectors located in portal-side cabinets and often use a furm of monitoring logic that is designed for detecting a moving radiation source. The 1 is sensitive, Category I monitors (operating with the same nuisance-alarm rate! may simply have much smaller radiation detectors or monitoring logic that is less effective for detecting moving radiation sources. The more sensitive, Category III monitors (operating with the same nuisance-alarm rate) may siniply have much larger detectors. Some Category III monitors: have the usual portal-side detectors supplemented by additional detectors placed overhead and underfoot. Another method of achieving Category' III performance in a Category II monitor has a person wait for a few seconds during monitoring instead of walking through. Besides these factor $\therefore$, there are other technical factors, such is portal width and radiation environment, that affect performance, although perhaps not enough to alter the performance categoiy. These factors are discussed further in Part 2. Note that changing the design of a monitor or its operating parameters to fit operational rules and regulations may affect the monitor's performance. An example of this is widening a portal to meet emergency exit requirements or to allow passage of carts: widening almost always reduces sensitivity.

\section{B. Neutron Monitor Categories}

The criginal Guide did not include performance categozies for neutror monitors because none were available then. A recent ASTM draft "Standard Guide to Laboratory Evaluation of Automatic Pedestrian SNM Monitor Performance" includes performance categories for both gamma-ray and neutron monitors. Table III lists categories for gamma-ray monitors that apply to both walk-through and wait-in monitors; Table IV lists categories for neutron nonitors. The standard procedures referenced in the footnotes are ones outlined in the ASTM guide.

The differences between the monitors in different categories are ones that have already been discussed. The NI and NII caterory monitors are typical of general-purpose 


\begin{tabular}{|c|c|c|}
\hline \multicolumn{3}{|c|}{$\begin{array}{l}\text { Table IV. Mass Detection Sensitivities in Pedestrian Neutron } \\
\text { Monitors }{ }^{a}\end{array}$} \\
\hline Category & Description & Piutoniurn $^{\mathrm{b}}(\mathrm{g})$ \\
\hline NI & Standard Neutron & 250 \\
\hline NII & Improved Neutron & 100 \\
\hline NIII & High-Sensitivity Neutron & 30 \\
\hline \multicolumn{3}{|c|}{$\begin{array}{l}\text { In a nominal } 20-\mu \mathrm{R} / \mathrm{h} \text { background intensity using standard } \\
\text { metallic test sources and procedures. } \\
{ }^{\mathrm{b}} \text { Low-burnup plutonium. For monitors having gamma-ray } \\
\text { sensitivity in addition to neutron sensitivity the plutonium } \\
\text { must be shielded in } 5-\mathrm{cm} \text {-thick lead. }\end{array}$} \\
\hline
\end{tabular}

monitors using different-sized plastic scintillation detectors and perhaps different forms of monitoring logic. Category NIII monitors are neutron-detection-based and benefit from having a lower background count rate than the general-purpose monitors that also sense gamma rays.

\section{APPLYING AUTOMATIC SNM PEDESTRIAN MONITOR TECHNOLOGY}

\section{A. Selecting a Monitor}

At each SNM monitoring location, the type and amount of SNM that is present usually governs the type of SNM monitor that is selected. At a uranium facility, the need to monitor for $\mathrm{HEU}$, which emits only gamma rays, limitr the choice to a gamma-ray monitor. In recent years, most commercial gamma-ray monitors have used plastic scintillators for reasons of low detector cost and good uniformity of detector response, so there is usually no option for detector type. The gamma-ray Category II monitor (which detects a 10-g HEU sphere or $3 \mathrm{~g}$ of HEU oxide encased in brass) has been widely used for SNM monitoring at material access areas and some protected area boundaries. A monitor in a higher performance category (see Table III) might be used if greater sensitivity for 10 detecting shielded HEU is needed. The tradeoff's in using a more sensitive monitor might be an increased monitor cost, an increase in nuisance alarms caused by changes in background radiation intensity, and perhaps an increase of a few seconds in monitoring time.

At a plutonium facility there are many choices. Plastic scintillation monitors in gamma-ray Category I (detects $1 \mathrm{~g}$ of plutonium) may provide adequate sensitivity for bare plutonium but perhaps not for shielded plutonium. A neutron-detection-based portal in neutron Category NIII (detects 30-g plutonium) of Table IV might be used together with the gamma-ray portal for detecting gamma-rayshielded plutonium. If high sensitivity for bare plutonium is not needed, the Category NIII neutron-detection-based portal might be used alone. In other circumstances, a gamma-ray monitor in a higher category (see Table III) might provide both adequate bare plutonium sensitivity and also adequate shieldedplutonium sensitivity by meeting neutron Category NI or NII performance levels in Table IV. Hence, both bare and shielded detection requirements would be satisfied in a single monitor. 
If both HEU and plutonium are present a a facility in different locations, the appropriate monitor or monitor combination can be chosen for each SNM monitoring location. If both HEU and plutonium are present at one location, monitoring requirements for both materials will have to be considered in choosing a monitor or munitor combination.

\section{B. Monitor Installation}

The original Ginide used a figure to illustrate an SIJM monitor installation along with a list of important points. Another list of important points is contained in the $A S_{\perp} M$ Applications Guide ${ }^{2}$ and summarized here in Appendix C. One point that has not been adequately emphasized is that only one person should be in or near the monitor at any time (see Fig. 3); however, enforcing the poir.t in routine monitoring is difficult. Posting signs and painting the floor near the monitor (the rug-like area in Fig. 3) with a message that only one person at a time is allowed may help. Also, bystanders should not be allowed near the monitor, and signs to that effect may be needed to help enforce this rule. The impact of more than one person in the area is that the monitor's background may be depressed by their presence, and a depressed backgrou:ld may lead to nuisance alarms when the people depart or to decreased monitor sensitivity while they are present.

A possible omission in the figure is an obvious metal detector, which may be used for metallic-shielding detection in a uranium area. In any case, hand-carried items are inspected and taken by a different route into the MAA. Another point bruight up in the ASTM guide

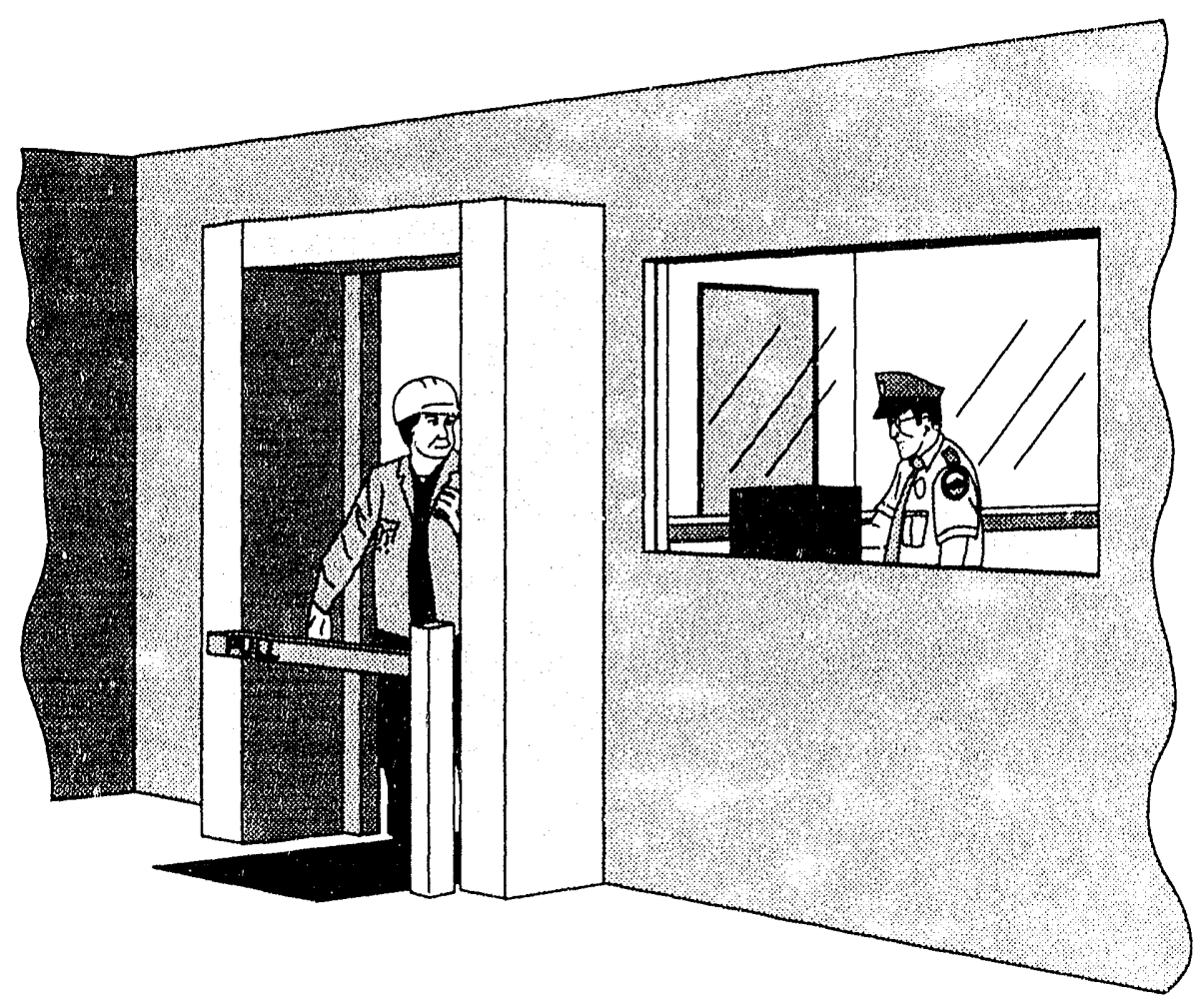

Fig. 3. Factors that influence SNM monivor performance are better illustrated in this new figure. The inspector is now in a hardened station, and the pedestrian no longer carries metallic items that would alarm a metal detector. 
is that the monitor's occupancy sensor can be used to sound a chime to aler the security inspector when a person is being monitored. This can be particularly helpful in attracting an inspector's attention when 'TV surveillance is used.

\section{Testing and Calibration}

Both the original Guide and the ASTM Applications guide discuss periodic calibration and testing. They both recommend quarterly calibration and testing with SNM and daily functional testing with small isotopic sources. Another form of testing, routine operational testing, was not mentioncd in either document but was being done at some DOE facilities as often as once a week. Objections to the way the operational tests were being conducted led the ASTM subcommittee to address the problem. T'he ASTM draft "Standard Guide to In-Plant Performance Evaluation of Automatic Pedestrian SNM Monitors" outlines an evaluation giving $95 \%$ confidence that a successful monitor has a $50 \%$ or greater detection probability for the test source, which means that if the evaluation is repeated, $95 \%$ of the repetitions are expected to give the true result. For minimum testing, the ASTM evaluation requires five detections in five passages, which may be routinely achieved by a monitor having a true detection probability much greater than $50 \%$ for the test source. For less sensitive monitors, a larger number of passages can be used for evaluation. The summary of the ASTM in-plant evaluation in Appendix $D$ gives a table of required numbers of detections for different numbers of passages.

The original Guide mentioned that manufacturers' calibration manuals often have to be supplemented with after-market documents based on local experience or published in conuection with an independent laboratory evaluation of the monitor. Another supplemental document on calibration is being developed by the ASTM. The title of the draft document is "Standard Guide to Procedures for Calibrating Automatic Pedestrian SNM Monitors," and it is expected to be published in 1991.

\section{COSTS OF SNM MONITORS}

Costs for general-purpose SNM monitors have not increased greatly in the interval since the Guide was published: hand-held search monitors are still available for $\$ 2000$ or less, and walk-through gamma-ray portals are available for less than $\$ 30,000$. The first pedestrian neutron portals are being offered at $\$ 45,000$ or less.

\section{OTHER TYPES OF SNM MONITORS}

\section{A. Instruments for Searching Paskages}

Besides pedestrian searches, DOE Order 5633.3 mentions physical or electronic searches of packages and containers as part of portal monitoring. Pedestrian monitoring areas have often used hand-held monitors for the purpose. Hand-held SNM search monitors are intelligent instruments with detection logic for sensing small signals as the inspector moves the monitor over a package. These hand-held instruments are listed at the beginning of the catalog in Part 3 of this report; the newer ones are available with optional plastic scintillation detectors that can detect neutron emission from shielded plutonium in packages.

Automatic monitors can provide higher sensitivity or more consistency in package searches. In plutonium areas, an automatic plastic-scintillator or neutron-detection-based pedestrian monitor may be suitabie for searching hand-carried $i$ ems for shielded plutonium. In other arer $s$, where package searches involve pass-through into a hardened 
station or require an inspector to leave a hardened area, a separate package monitor could improve package monitoring. Although systems for monitoring waste-containing packages and either ejecting them or transporting them across an MAA boundary are not uncommon, ${ }^{5}$ similar, less complex systems for entry control stations are not presently available. The closest commercial products $^{6}$ that are most likely to have adequate sensitivity (sometimes called "lunch-box monitors") are only semi-automatic, may weigh more than a ton, and may not have a conveyor or other means for passage through a perimeter. Los. Alamos has a demonstration unit, which shows technology that could be adapted to existing entry control stations (Fig. 4).

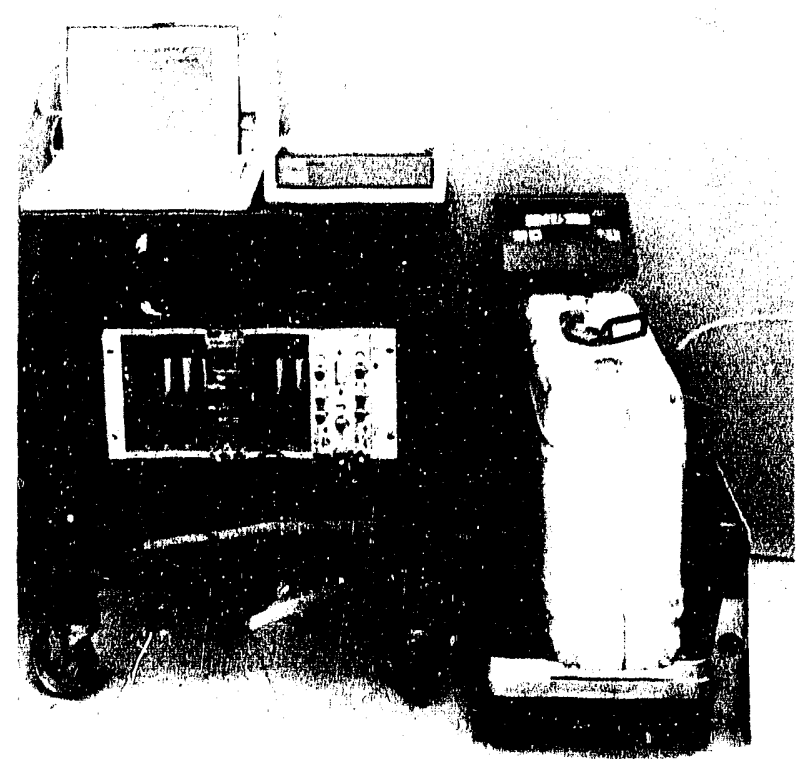

Fig. 4. The demonstration unit uses a load-cell balance to weigh packages and has radiation detectors both under and beside a package to measure radiation intensity. The basic concept could be used in sizes ranging from small systems for monitoring pocket items to larger systems with suitcase-size capacity.
The demonstration unit comprises commercially available hardware that has been assembled into a package monitor. A personal computer communicates with a load-cell balance that weighs packages and a radiation measurement system that uses plastic scintillation detectors to sense gamma rays and neutrons emitted from packages. Both the proximity of the radiation detectors and the possibility of monitoring for a few seconds provide improved sensitivity for detecting shielded uranium. Package weighing detects an unacceptable amount of shielding.

Commercial implementations of this type of monitor should be possible in a range of sizes. Small systems not much larger than a hand-held monitor coula be wall mounted in pedestrisn monitoring areas adjacent to hardened guard stations for monitoring pocket items that alarm metal detectors. Larger systems could be incorporated into perimeters so that packages entering or leaving could be inserted on one side of the perimeter and retrieved from the other side after monitoring.

Other concepts for monitoring packages include active means of interrogation, such as neutron interrogation. Although these systems are very expensive, large, and not readily adapted to entry-control stations, one facility has proposed a way to make active package monitoring more practical. Suspicious items would be collected from departing pedestrians and placed in a single container, which would then be transported a short distance to an active neutron assay system located in a nearby laboratory area. After a short, active interrogation for exit clearance, the container would be returned to the entry station and the items distributed to their owners. 


\section{B. Waste-Stream Monitors}

Waste monitors is another monitor category that has received more attention in DOE Order 5633.3. Besides automatic monitors for low-density waste, it is not uncommon for liquid and gaseous waste streams to be monitored with radiation instruments for reasons of process control, accountability, or environmental concern. In some cases, these instruments may satisfy security needs as well. One specialized perimeter security monitor is commercially avaiiable for monitoring sanitary fluid waste lines with radiation detectors to detect tne passage of plutonium (see Fig. 5). Other means, such as inserting a trap or fiiter in a fluid line, can prevent the theft of large or weighty SiNM items.

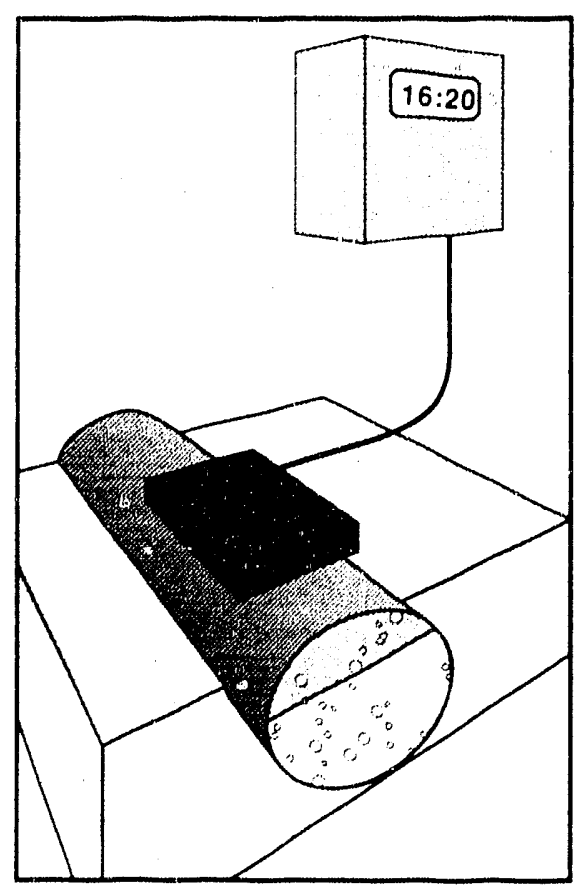

Fig. 5. The TSA Systems CFM-441-2 Fluid Monitor uses two detectors and the time intervals between their alarms to detect plutonium passing through sanitary waste lines.

\section{Hand-Held Confirmation Instruments}

Confirmation measurements test the consistency of attributes for a particular item or material with expectations for that general type of material. These instruments are sometimes used to confirm or verify that a material emitting radiation is or is not a particular type of SNM. The use for confirmation instruments in portal monitoring is normally to confirm that radioactive materials detected in an SNM monitor are inot SivM. A very general way to make confirmation measurements uses a gamma-ray spectroscopy system ${ }^{i}$ to identify the isorcpe producing an alarm. Hand-held instruments also can be effectively used for the purpose when plutonium is the form of SNM involved.

Hand-held confirmation instruments for plutonium can use either the gamma-ray or neutron signature of plutonium to confirm its presence or absence. Two types of instrument are commercially available. ${ }^{8}$ The gamma-ray instrument measures the $330-450 \mathrm{keV}$ gamma region and strips it of underlying background for a confirmation measurement. The neutron instrument moderates fission neutrons from plutonium and measures them for confirmation. Used together, the instruments can give a higher degree of confirmation that plutonium is not present. Figure 6 shows the neutron instrument in use io confirm that plutonium is not present in a non-nuclear flight-test warhead. Confirmation instruments are further discussed in Sec. VI of Part 2. 


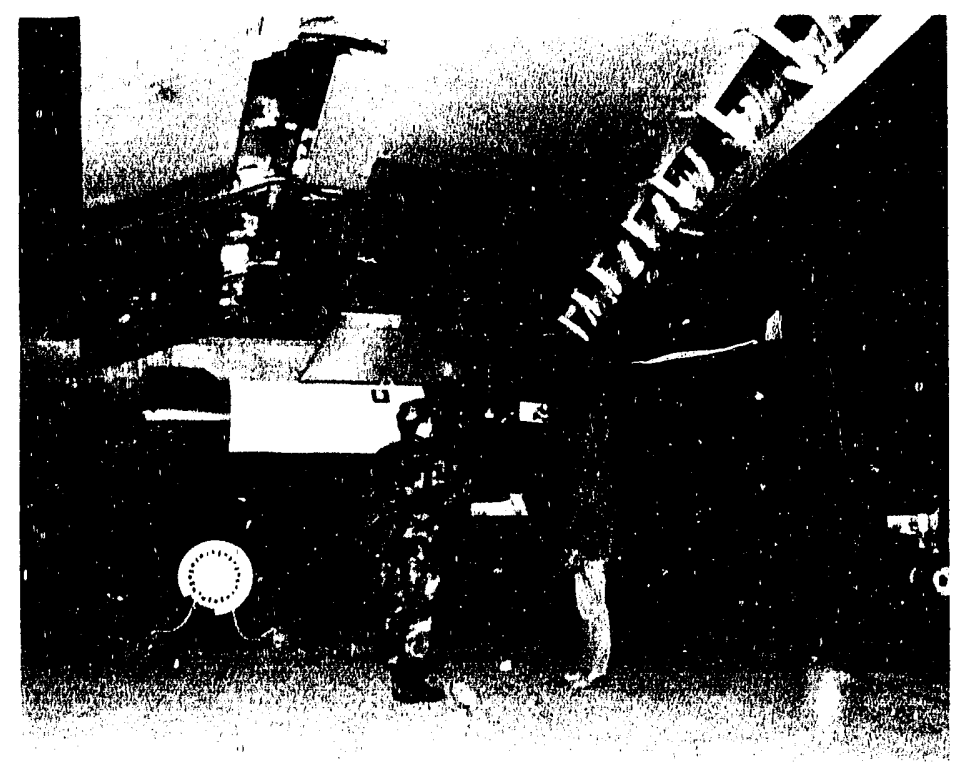

Fig. 6. Pre-flight verification that warheads are non-nuclear test assemblies is routinely being done with the hand-held neutron instrument. 


\section{PART 2 \\ THE TECHNICAL BASIS OF RADIATION MONITORING}

\section{INTRODUCTION}

The technical discussion in Part 2 of the Applications Guide (LA-10633-MS) covered the history of radiation monitoring and the technical basis for gamma-ray monitoring, which has changed very little since that time. However, as mentioned in Part 1, there is now more emphasis on methods for evaluating SNM monitor performance, and instruments are now available to confirm whether or not the radioactive material causing an alarm is SNM. Other topics in the Guide could have received more emphasis, for example, detection algorithms and the details of monitor construction that can affect performance. These topics and the technical basis for neutrondetection-based monitors are discussed in the following sections.

\section{PERFormanCe ASPECTS OF GAMMA-RAY PORTAL DESIGN}

As mentioned in Part 1, both the size and number of detectors and the monitoring algorithm used in a garnma-ray SNM monitor may influence its performance. The influence of detector size is partly related to the way a monitor calculates its alarm threshold. A commonly used alarm threshold $(A)$ is the sum of the background (B) and a multiple $(\mathrm{N})$ of the square root of the background, or

$$
A=B+N \sqrt{B} .
$$

At this threshold, a monitor's statistical nuisance-alarm rate remains constant as background (or detector size) changes. But if the detector size increases, the threshold signal needed to alarm (S) becomes a smaller fraction of background. The fraction is proportional to the square root of the background divided by background, or 1 over the square root of the background:

$$
\frac{S}{B} \propto \frac{1}{\sqrt{B}} .
$$

Hence, if the monitor's detectors (and background) are doubled in size, the signal needed to alarm the monitor is about a $30 \%$ smaller fraction of background. If signals also increase in the same proportion as detector area, then signals $30 \%$ smaller can be detected. However, note that not all monitors use this method of detection. A few monitors use an algorithm that preserves detection sensitivity rather than nuisance alarm rate by keeping the alarm threshold either constant or a fixed fraction of background. This type of monitoring logic is rare, but it has been used in SNM monitors that, as a result, do not benefit from increased detection sensitivity with larger detectors or longer monitoring times.

Another way of increasing the total detector size is by adding individual detectors, perhaps underfoot or overhead. In this case, overall performance is enhanced by making the 
detection sensitivity more uniform throughout the portal. When this is done, the least sensitive region may be at the waist, where'as without the head and foot detectors, the foot region may have been the least sensitive and the waist region th : most sensitive. Adding head and foot detectors is usually sufficient to raise the performance of a Category II portal to that of Category III. This improvement corresponds to being able to detect signals that are one-half as large."

Other changes in monitor design or operating situation can improve sensitivity. The following rules of int $\mathrm{mb}$ give an idea of how significant some changes in a monitor, its way of operating, or the materials being monitored can affect operation in a plant environment. If a walk-through portal monitor is capable of detecting a given spherical mass of metallic material $50 \%$ of the time, then the following smaller masses of material may be detected if the indicated change is made.

1. Nine-tenths of the original mass may be detected if the portal spacing is reduced from $79 \mathrm{~cm}$ (31 in) to $66 \mathrm{~cm}$ (26 in). Further reducing the spacing may decrease sensitivity instead of increasing it because the occupant then causes a larger decrease in the monitor's background counting rate.

2. One-half of the mass may be detected if the background is reduced from $25 \mu \mathrm{R} / \mathrm{h}$ to $10 \mu \mathrm{R} / \mathrm{h}$.

3. One-half of the mass may be detected if the pedestrian's body is not in the portal to provide shielding. This effect is significantly diminished in areas with relatively low background. The closest practical approach for achieving this improvement is to partially eliminate body shielding by having the pedestrian stop and face the radiation detectors during monitoring.

4. One-half of the mass may be detected if the person is slowed to one-half normal speed.

5. One-third of the mass may be detected if the person is stopped in the portal and monitored for a few seconds with a wait-in monitoring algorithm.

6. One-third of the mass may be detected if the material is in the form of loose powder or an aluminum alloy instead of pure metal.

Some of these changes can be combined. For example, both stopping pedestrians and having them face the detectors can be more effective than either one alone. Other factors are difficult to change: background may be impossible to reduce, portal widths must be sufficient for easy passage, and the forms of process material do not often vary.

\section{THE EFFECT OF DETECTION ALGORITHMS ON PERFORMANCE}

\section{A. Detection Sensitivity}

A wait-in monitor usually makes one single measurement during the time it monitors a pedestrian. The same should not be true for a walk-through monitor that has no way of knowing precisely where a pedestrian may be at any moment. If free passage is allowed, a pedestrian could pass through a singlemeasurement monitor after the monitoring measurement had finished, for example, by

"The expected decrease in detected radiation intensity for $3-\mathrm{g}$ instead of $10 \mathrm{~g}$ spheres of uranium (which define Category II and III performances) is $(3 / 10)^{2 / 3}=0.45$. 
closely following the preceeding person. Even if this scenario were prevented by a good "one person in the portal" rule, there still may be a way to keep radioactive material at a distance during a single monitoring measurement. With one recent exception, walk-through portal designs have always included continuous monitoring to prevent such schemes.

At the very least, walk-through monitors have made a sequence of short-interval measurements, instead of just one. The scquence of measurements doesn't necessarily guarantee that a person will be in the portal for an entire measurement; it does guarantee that the person will be there for at least part of one or more measurements. Hence, therc is never a time when detection sensitivity is lacking.

A sequence of monitoring measurements can also improve overall performance. For example, if each of two measurement results during passage has a $40 \%$ chance of detecting the source, then the overall detection probability for the passage is at least $64 \%$. Even if the alarm threshold were increased to keep the nuisance-alarm rate per passage the same for two measurements as for one, the detection probability still improves. Most often, using a sequence of short monitoring measurements offers the highest sensitivity at a given nuisance-alarm rate in a walk-through portal monitor. The moving-average-scaler and sequential-probability-ratio methods described in Ref. 9 are the most common measurement methods used in commercial monitors today.

\section{B. Nuisance-Alarm Rate}

A small change in a detection algorithm may not be worthwhile if it adversely affects nuisance-alarm rates to a much greater degree than it improves detection sensitivity. For example, decreasing an alarm threshold from 4 to 3 standard deviations (std dev) above the average background permits $\mathrm{d} r$ ucting a signal $75 \%$ as intense as originally detected. On the other hand, tive nuisance-alarm rate could increase by a factor of 30 or more. Another small change, decreasing the background counting time, can also adversely affect the nuisance-alarm rate. Although shorter background measurements make the alarm threshold more timely, each background result and derived alarm threshold is less precise. Nuisance alarms result from statistical variation in both quantities involved in comparing a monitoring measurement with an alarm threshold; hence, the precision of each quantity affects the nuisance-alarm rate. Figure 7 illustrates how a nuisance-alarm probability depends on the relative amount of time used for background measurement. If background measurements are not sufficiently timely, using a frequently updated moving average of short background measurements

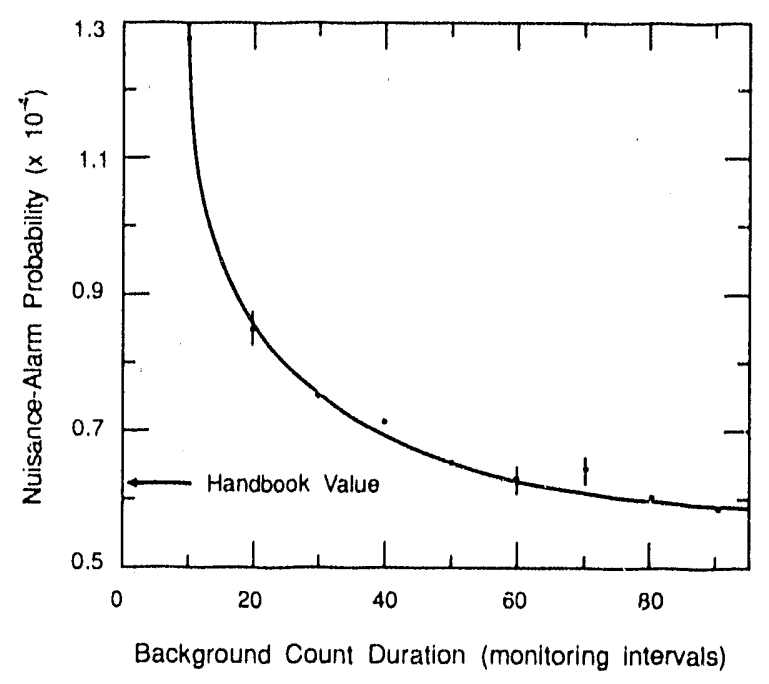

Fig. 7. Nuisance-alarm probability as a function of the relative amount of time devoted to background measurement. The plotted values represent observed deviations of 4 std dev (two-sided) or more from the mean. 
may help. This approach is particularly useful if traffic is heavy and interfers with a single long measurement.

\section{A DETECTION ALGORITHM FOR PROTRACTED THEFT}

A novel method for SNM detection was designed for detecting protracted theft with a walk. through monitor. The method has not yet been applied or evaluated in an operating environment, ${ }^{*}$ but it seems an ideal adjunct to normal SNM monitor operation. The algorithm employs data from pedestrian passages through a monitor over a period of time (one or more weeks) and is most sensitive when the monitoring system identifies each pedestrian passing through. Developed by Henry and Pratt, ${ }^{10}$ the algorithm measures a net count during a pedestrian's passage from the difference between a short monitoring measurement and the average background from equally short measurements just before and just after passage. Although individual net measurements of this type are imprecise, they can be very useful when averaged over a number of occasions.

The Henry-Pratt method can be used to monitor populations without identifying the individuals. In this case, average net monitoring measurements for a week or more can be obtained, and the incoming averages can be compared with the outgoing averages. $A$ significantly larger outgoing average would indicate protracted theft of small amounts of SNM by some members of the population. Sensitivity is greatest when each pedestrian is identified, and the monitoring measurements are automatically recorded in individual accounts. In that case, any net results from repeated theft by an individual are concentrated in one account, whicn offers great sensitivity and identifies the responsible individual. More facilities are beginning to use electronic identification for entry authorization, and one of these systems may eventually lead to an opportunity to apply the method to individuals.

The hardware for the Henry-Pratt method is relatively simple. The portal monitor must have an occupancy sensor at both its entry and exit to sense the period of occupancy and the direction of motion, incoming or outgoing. The measurements and analysis can be done in a separate microprocessor, if not in the monitor's microprocessor. Results of the analysis should be stored in individua! files in a host computer, which can then periodically tally and compare incoming and outgoing averages and report significant differences.

\section{SNM MONITOR PERFORMANCE EVALUATION}

The Applications Guide discussed portalmonitor, walk-through testing in general terms. Daily testing can be done with an isotopic source, which has a source strength that gives a signal near to that of the SNM to be detected. Other periodic testing with SNM or equivalent sources can be performed with a procedure that gives $95 \%$ confidence that the. results confirm a $50 \%$ or greater detection probability for the test source. The ASTM draft "Standard Guide to In-Plant Performance Evaluation of Automatic Pedestrian SNM Monitors" gives additional information on in-plant testing; its information on nuisancealarm testing is summarized here in Appendix A, and its information on sensitivity

* An in-plant evaluation is needed to examine the influence of such factors as radon daughters attached to clothing on practical detection thresholds. 
testing is summarized in Appendix D. Table DII lists the required number of detections to achieve $95 \%$ confidence of a $50 \%$ or greater detection probability for different numbers of trials between 5 and 30 .

Note that performance testing is a reliable way to verify that a portal monitor is operating properly or to discover that it is not. Tracking nuisance alarms can provide timely notice of an excess that may indicate the need for repair. Similarly, decreased detection sensitivity can reveal misoperation. Other maintenance procedures, such as recalibration or variance analysis, cannot substitute for performance testing during routine operation.

The ASTM guide also gives information on encapsulating test sources that applies to packaging a process material for use as a test source. Uranium encapsulation is described as thin plastic or thin aluminum $(<0.32 \mathrm{~cm}$ thick) to reduce unnecessary radiation absorption in the encapsulation. Plutonium encapsulation includes a filter to reduce the impact of $60-\mathrm{keV}$ gamma rays from ${ }^{241} \mathrm{Am}$, a plutonium decay product that will build up in time and emit increasing amounts of $60-\mathrm{keV}$ radiation. The filter is cadmium $(0.04 \mathrm{~cm}$ to $0.08 \mathrm{~cm}$ thick $)$ and is an integral part of the source encapsulation. The protective encapsulation is in as many layers as local rules require of aluminum layers $(<0.32 \mathrm{~cm}$ thick) or thin layers $(<0.16 \mathrm{~cm}$ thick) of stainless steel or nickel to reduce unnecessary radiation absorption.

The ASTM guide also discusses alternative test sources to use when plutonium is not available or can not be used. Table DI in Appendix D lists the equivalent amounts of HEU or ${ }^{133} \mathrm{Ba}$ that can be used as a gammaray substitute for plutonium. Section III of Appendix D also lists equivalent amounts of an alternative neutron source for plutonium, ${ }^{252} \mathrm{Cf}$, which emits neutrons from spontaneous fission as does plutonium. Note that ${ }^{252} \mathrm{Cf}$ also emits gamma rays and must be shielded in 5-cm-thick lead if the neutron sensitivity of a plastic scintillation detector is being evaluated. A word of caution on these alternative sources is that they sometimes decay much faster than the nuclear materials. The half-life of ${ }^{133} \mathrm{Ba}$ is 10.7 years, and ${ }^{252} \mathrm{Cf}$ is 2.64 years. If precisely the amount needed is purchased, the substitute source will have a relatively short working lifetime. Larger sources than initially needed can be purchased to extend the working lifetime for the source. In any case, the sources should be replaced on a regular schedule as their activity falls below the desired amount.

\section{SNM CONFIRMATION INS'TRUMENTS}

\section{A. Confirmation Measurements}

An SNM confirmation measurement is one that is made to test whether some at ribute or characteristic of a material is consistent with it being a particular type of SNM. The radioactive attributes of SNM offer a convenient means to confirm that a material causing a portal monitor alarm is or is not SNM. These attributes are the neutron emission of plutonium and the gamma-ray emission of all types of SNM. Low-energy radiation, such as the $60-\mathrm{keV}$ gamma ray that builds up in plutonium and the $100-\mathrm{keV} x$-rays in uranium, confirms unshielded SNM. ${ }^{11}$ Whereas, plutonium in shielding can be confirmed by the band of gamma rays between 330 and $450 \mathrm{keV}$ and by its neutron emission. Metallic, highly enriched uranium has no useful neutron emission, but its $185-\mathrm{keV}$ gamma ray penetrates thin packaging materials. Another uranium gamma ray at $2.6 \mathrm{MeV}$ from the minor isotope ${ }^{232} \mathrm{U}$ is very penetrating and has been used for confirmation measurements. ${ }^{12}$ However, the 
${ }^{232} \mathrm{U}$ isotope and its daughters are present in small, varying amounts.

Background radiation can limit the utility of a confirmation measurement. More than one radioactive material may be present in a source causing an alarm, and conflicting radiation may be present in background. Compton-scattered background radiation in gamma-ray peak regions can be removed using measurements in adjacent regions to estimate the underlying Comptnn contribution. Conflicts in natural background, sucis as the naturally occurring 2.6-MeV gamma ray, can be removed by separately measuring background.

\section{B. Confirmation Instruments}

Instruments for gamma-ray confirmation measurements at portal-monitoring stations range from computer-based, gamma-ray spectroscopy systems using high-resolution detectors to small hand-held instruments with $\mathrm{NaI}(\mathrm{Tl})$ scintillators. Small, hand-held neutron instruments using europium-activated, enriched lithium iodide scintillators $\left[{ }^{6} \mathrm{LiI}(\mathrm{Eu})\right]$, as well as other instruments, are commercially available for neutron measurements.

The spectroscopy systems ${ }^{7,13}$ offer the most information about a gamma-ray-emitting material. The emitting isotopes can be identified and, in one case, ${ }^{13}$ medical isotopes can be identified as being in vivo or present as source material. The drawbacks to spectroscopy systems are their initial expense, size, daily upkeep, and need for a trained operator. The vehicle-mounted system described in Ref. 7 can provide the confirmation service at many different locations; however, upkeep and an experienced operator are still necessary. Hand- held instruments offer less specific results, usually just yes or no to the question of whether SNM is present, but their initial cost is less, and less training may be needed for use.

Instruments for making neutron confirmation measurements at portal-monitoring stations are less specific than the gamma-ray instruments and only confirm the presence of a neutron emitter that may or may not be plutonium. Conversely, the instrument can rule out the presence of any neutron emitter, including plutonium, when its measurements do not significantly exceed backgiound.

\section{Los Alamos Instruments}

L s Alamos developed two portable, microprocessor-based instruments for confirmation measurements, which are now commercially available. ${ }^{8}$ These instruments stem from SNM search instruments developed and commercialized by Los Alamos. The hand-held instruments are small, readily portable, battery-powered, and have internal radiation detectors for ruggedness and microprocessor control for versatility. A second version of one instrument can use a large, external gammaray scintillator for detecting $2.6-\mathrm{MeV}$ gamma rays or a large shielded neutron proportional counter for detecting neutror. in areas of high neutron background.

1. Neutron Instrument. The Los Alarnos neutron-verification instrument is available from two manufaciurers: TSA Systems and Jomar Systems, Inc. The TSA Systems ${ }^{*}$ NNV-470 (Fig. 8) incorporates human-factors engineering that allows it to be used by relatively untrained people who may have to work outside in a cold environment. It has a

* TSA Systems, Ltd., 1820 Delaware Place, Longmont, CO 80501 (303) 651-147. 
large handle and membrane switches that make it can easy to operate by a person wearing gloves. The Jomar Systems ${ }^{*}$ JHH-22 is a similar instrument with a conventional handle and switches. Each instrument uses a moderated, 2.5 -cm-diam ${ }^{6} \mathrm{LiI}(\mathrm{Eu})$ scintillator to convert gamma rays and neutrons to light, which induces current and voltage pulses. The instruments use a level discriminator to select the large pulses produced by neutrons for measurement, and they display the measurement results on an LCD.

'The number' of neutrons counted determines whether or not plutonium is present. The instrument measures for a preselected time period up to $99 \mathrm{~s}$ long. When the result is displayed, the instrument beeps and starts a new measurement whi'e holding

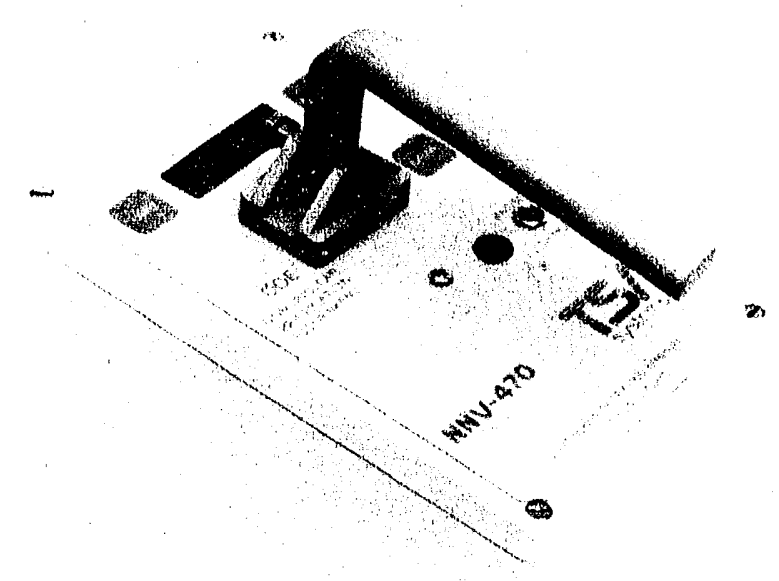

Fig. 8. The TSA Systems NNV-470 is a hand-held instrument designed to detect and measure only neutrons in the mixed radiation fields present in SNM access areas. the present result in the display. Procedures may require recording several measurement results as part of confirmation. Verifying normal operation of the instrument is also part of confirmation. If a neutron source is not available, the instrument has a second mode that can be used to verify operation. The check mode uses a second level discriminator set very low so that gamma rays can be detected.

2. Gamma-Ray Instruments. The gamma-ray verification instrument developed by Los Alamos and Jomar is the Jomar JHH-31. It has an LED-stabilized sodium iodide scintillation detector to convert gamma rays to light and then to electrical current and voltage pulses. For plutonium verification, the JHHI-31 can be precalibrated to measure the unshaded plutonium pulse-height region (330-450 keV) above channel 200 in Fig. 9. The shaded regions to the right and left are also measured and used to estimate the Compton backgrounu underlying the peak. agion so that it can be subtracted to give a net result.

For uranium verification, the JHH-31 can measure the $185-\mathrm{keV}$ gamma-ray intensity stripped of underlying Compton background using one of two methods. One method is the same described in Fig. 9; the other uses a single, higher energy region and a predetermined calibration factor to estimate the Compton background. In either case, the net result is proportional to the enrichment of the surface of the uranium. Hence, the instrument can both identify uranium and estimate its enrichment when standard shapes and sizes of uranium are measured.

* Jomar Systems, Inc., 110 Eastgate Dr., Los Alamos, NM 87544 (505) 662-9811. 


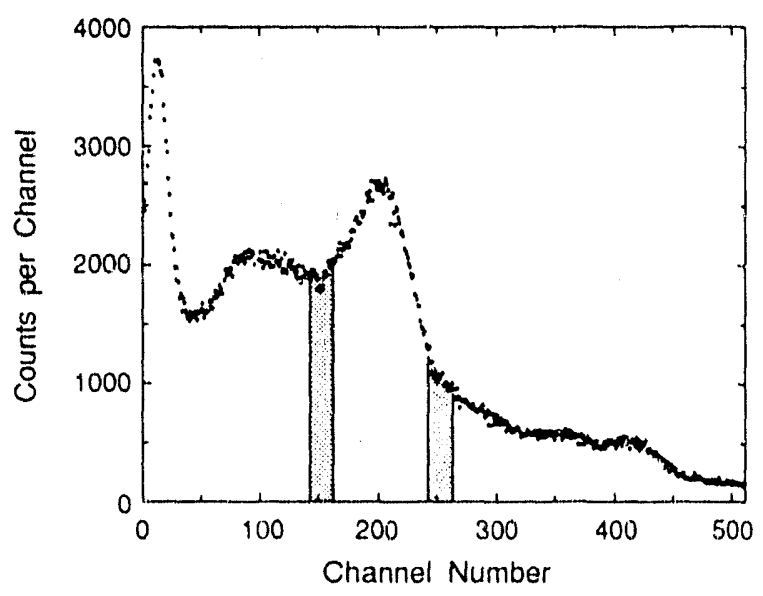

Fig. 9. The plutonium region from $330-450 \mathrm{keV}$ stands out in this mixed gamma-ray spectrum. The shaded side rogions are used to measure the Compton-scattered radiation intensity underlying the central peak region.

The Jomar Systems JHH-41 is similar to the JHH-31, but it can use external detectors and has an RS232 port to output data for subsequent computer storage or analysis. The instrument operates with either Jomar's shielded, neutron-assay probe ${ }^{14}$ (SNAP-I) detector or a large external $\mathrm{NaI}(\mathrm{Tl})$ deteciur. The SNAP-II detector is well shielded f:om neutron background and use ${ }^{3} \mathrm{He}$ proportional counters to detect neutrons alone. Its detection efficiency is greater than the ${ }^{6} \mathrm{LiI}(\mathrm{Eu})$ scintillator instruments, which shortens measurement time; however, the SNAP-II detector is heavier and less portable. The large external $\mathrm{NaI}(\mathrm{Tl})$ detector will also be less portable, but it can more effectively be used to measure 2.6-MeV gamma rays for confirming uranium. The presence of uranium is more easily confirmed than its absence because the 2.6- $\mathrm{MeV}$ gamma-ray intensity may be too low or absent in some uranium.
As in the neutron instrument, the number of gamma rays counted determines whether SNM is present. Again, the instrument measures for a preselected time period up to $99 \mathrm{~s}$ long. When the result is displayed, the instrument beeps and starts a new measurement while holding the present result in the display. The instrument has a second mode that measures all gamma rays above a threshold that can be used with background radiation to verify that the instrument is operating.

\section{Other Instruments}

The Los Alamos "IDENT" is a microprocessor-based instrument ${ }^{11}$ that uses a thin $\mathrm{NaI}(\mathrm{Tl})$ scintillator to measure the $\mathrm{x}$-ray energy range. It displays both multichannel pulse-height spectra and counting information for confirmation purposes. Unfortunately, it is not commercially available, and its thin radiation detector is suitable for confirming only bare or lightly packaged materials.

In the final steps of development is the TSA Systems HHMCA, which uses a $\mathrm{NaI}(\mathrm{Tl})$ scintillator that is stabilized when the instrument is first turned on. It measures background spectra and automatically subtracts background from subsequent item measurements before displaying the result as a spectrum on an LCD. The instrument has switch-selected options to calcuiate and display confirmation measurement result so for selected spectral regions. It also has an RS 232 port for data transfer, and the manufacturer provides an IBM-PC communications program. Although the HHMCA is not yet fully developed and free of problems, many have been sold. At present, the lack of voltage regulation prevents the stabilization from working, and the manufacturer plans to recall instruments for modification once the remaining problems are identified and solved. 


\section{E. Confirmation Measurement Steps}

Confirmation measurements require the following steps.

\section{Check the instrument for proper} operation. A standard source of radiation, such as a radiation source or background radiation, is used to check the instrument for normal operation. The results should be similar to previous results.

2. Measure the background. Background is measured near $(\sim 2 \mathrm{~m})$ the object to be confirmed but with the operator's body between the object and the hand-held instrument. No other shielding material, radioactive material, or bystanders should be close. The background measurement procedure should duplicate the confirmation measurement procedure including the recording of results.

3. Perform the measurement. Once the instrument is placed on the object to be confirmed, make measurements and record thiem.

4. Analyze the measurements. Net results are the difference between the confirmation measurement and background results. Based on experience, significantly large, positive net measurement values for neutron and/or gamma-ray measurements confirm the presence of particular types of SNM.

\section{A BRIEF HIS'TORY OF NEUTRON PEDESTRIAN MONITORS}

Neutron monitoring has been an attractive goal as a means to detect neutron-emitting forms of nuclear materials in both international and domestic safeguards. The benefits of neutron monitoring are twofold: neutron backgrounds are usually low, and neutrons emitted by nuclear materials readily penetrate containers to give a signature for the presence of nuclear material in proportion to its mass.

Serious attempts at neutron monitoring began with work done by J. T. Caldwell et al. ${ }^{15}$ to develop a more uniform-sensitivity method than could be achieved with gamma-ray methods for monitoring vehicles crossing the perimeter of a uranium enrichment plant. Caldwell's concept was to enclose the vehicle in a polyethylene-walled tunnel lined with ${ }^{3} \mathrm{He}$ neutron proportional counters on the side walls. Shortly thereafter, Caldwell transferred the technology to pedestrian monitoring in the form of a polyethylene-walled booth ${ }^{16}$ having proportional counters in its ceiling and floor. A prototype commercial neutron pedestrian monitor ${ }^{17}$ of a different type appeared shortly thereafter. The commercial monitor failed to find customers, apparently as a result of the expense of its prototype neutron detectors, which were lithium-oxide-walled, multiwire proportional counters. The UK AERE Harwell later achieved commercial success with another monitor, ${ }^{18}$ which is still available, that uses as many as 20 , large $\mathrm{BF}_{3}$ proportional counters. This novel monitor copes with its relatively temperamental $\mathrm{BF}_{3}$ counters by having integral electronics for each counter so that any noisy counters can be detected and automatically isolated from the system. The Applications Guide included this monitor as the last entry in the catalog section.

In the meantime, Caldwell's original detector concept had been modified for another purpose: Caldwell et al. ${ }^{19}$ designed modular detector units that could be stacked around radioactive waste containers for neutron assay of the contents (Fig. 10). Each module was a hollow polyethylene chamber containing several ${ }^{3} \mathrm{He}$ proportional counters. Caldwell's 
chamber detector was modified for SNM monitoring by $\mathrm{K}$. Coop et al. ${ }^{20}$ and eventually became the basis for a more eccnomical neutron-detection-based pedestrian monitor. ${ }^{21}$ The pedestrian monitor is a walk-through portal monitor that has a single ${ }^{3} \mathrm{He}$ proportional counter in each of the detectors that form its portal. Prototypes of this portal monitor have been evaluated in laboratory and plant situations, and the design is presently being commercialized.

The following sections give background information related to neutron portal monitoring and further describe the operation of the new neutron-detection-based monitors.
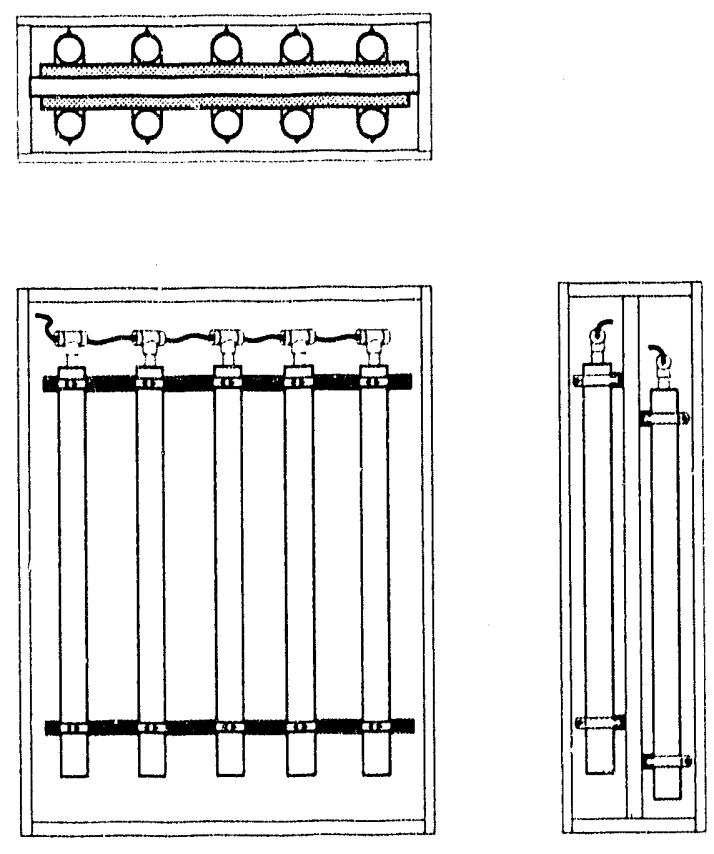

Fig. 10. Caldwell's neutron-chamber detector was constructed in modular form for stacking around large waste containers for passive neutron measurements.

\section{NEUTRON SOURCE CHARACTERISTICS}

\section{A. Backgrounds}

Natural neutron background intensities are very low compared to gamma-ray background intensities. Neutron portal monitors may have backgrounds of some tens of counts per second, whereas gamma-ray portal monitors would have backgrounds of some thousands of counts per second. Neutrons in natural background primarily stem from cosmic-ray interactions in the atmosphere. As a result, their intensity varies with both latitude and altitude and decreases by about a factor of 5 between the highest and lowest altitude DOE facilities. The very low neutron background helps to make neutron-detection-based monitors very sensitive.

Other neutron backgrounds at DOE facilities from process nuclear materials originate in spontaneous fission and $(\alpha, n)$ reactions. Besides producing background neutrons, these mechanisms are also the source of the signals detected in neutron-detection-based monitors.

\section{B. SNM Neutron Source Strengths}

Reference 3 provides information on the relative amount of neutron emission by different forms of SNM. The predominant source of neutrons in low-burnup plutonium is the isotope ${ }^{240} \mathrm{Pu}$, which emits about $1000 \mathrm{n} / \mathrm{s}-\mathrm{g}$ of the isotope. Low-burnup plutonium contains about $6 \%$ of this isotope; hence, the rule of thumb is to expect about $60 \mathrm{n} / \mathrm{s}-\mathrm{g}$ in small quantities of metallic, low-burnup plutonium. Safeguards Category I quantities of metallic plutonium may have an increased neutron source strength from induced fissions in the material. Plutonium oxide may emit additional 
neutrons from the $(\alpha, n)$ reaction on oxygen, and the emission rate per gram may increase by half or more, in dry oxide [moisture reduces the $(\alpha, n)$ yield]. In $\mathrm{PuF}_{4}$, the $(\alpha, n)$ neutrons from fluorine can predominate fission neutrons by two orders of magnitude; hence, plutonium fluorides can be a major contributor to background radiation at a facility. Other contributors to $(\alpha, n)$ reactions are the oxygen in nitrates and nitrate solutions and the aluminum in plutonium alloys.

Spontaneous fission rates in uranium are much too low to contribute useful signals for monitoring. The mosi: appreciable neutron emission is in fluorides, where the $(\alpha, n)$ emission rate can be as much as $3 \mathrm{n} / \mathrm{s}-\mathrm{g}$ of HEU. Still, this is only $5 \%$ of the fission neutron emission rate from low-burnup plutonium.

\section{Other Sources}

Neutron sources using the same production mechanisms as SNM, spontaneous fission and $(\alpha, n)$ reactions, are commercially available and may be encountered in some situations. The isotope ${ }^{252} \mathrm{Cf}$ emits neutrons by spontaneous fission and offers a convenient alternative test source for neutron-detection-based portals. Its short (2.64-year) half-life limits its useful lifetime. Other neutron sources based on $(\alpha, n)$ reactions, such as ${ }^{241} \mathrm{Am} / \mathrm{Li}$ or ${ }^{241} \mathrm{Am} / \mathrm{F}$, can provide a long-lived source of neutrons having an average energy near californium.

\section{Neutron Interactions with Materials}

\section{Neutron Interactions in Detectors.} Unlike gamma rays, the energy of neutrons is not as useful for establishing regions of interest for monitoring. But neutron energy is an important characteristic for detection, and there are two types of detector: fast (energetic) neutron detectors, such as plastic scintillators; and thermal (low-energy) detectors, such as neutron proportional counters. Plastic scintillation detectors depend on the scattering of fast neutrons by protons, which then recoil and produce ionization and detectable light. In contrast, the neutron proportional counters used in neutron-detection-based monitors most readily detect thermal neutrons. Thermal neutrons, named after neutrons in thermal equilibrium with the environment, can be captured by a converter-gas nucleus in a proportional counter and converted to charged reaction products that lead to a detectable signal. Because neutrons from SNM are fast, part of a neutron-detection-based monitor design is devoted to slowing down the neutrons so that they can be detected. A material, such as polyethylene, slows neutrons through collisions with nuclei in the material, a process called moderation. Hydrogen-rich materials are particularly good moderators.

\section{Neutron Interactions in Shields.}

Neutron-shielding materials also depend on moderation and capture to absorb neutrons so that they cannot be detected. Polyethylene is a good shielding material because it is a good moderator. Moderated neutrons that remain in the polyethylene can be captured by hydrogen nuclei, which subsequently emit a $2.2-\mathrm{MeV}$ gamma ray. Some polyethylene shielding material is loaded with boron, which provides an alternative capture nucleus that produces a much lower energy gamma ray and lessens the gamma-ray dose from the shield. Borated polyethylene, still a good moderator, allows some neutrons to escape and be detected in a proportional counter. Other common shielding materials for energetic neutrons, such as water and paraffin, are also good moderators. Still other materials advertised as being nighly efficient neutron shields are simply efficient absorbers of thermal neutrons. Shielding energetic neutrons always requires a great 
deal of moderating material in addition to efficient absorbers.

\section{E. Characteristics of Diversion Signals}

One difference between detecting sources of gamma rays and sources of neutrons in a portal monitor is that radiation scattering is much more significant for neutrons. Scattering makes the foot region of a neutron portal a sensitive region in contrast to a gamma-ray portal, which may be least sensitive in the foot region. A concrete floor scatters neutrons, producing, in effect, a mirror image of a source in the floor, which increases the neutron signal. Neutron portal design carries this concept further by placing a thick polyethylene roof over the portal to scatter neutrons down into the detector. This design makes neutron detection sensitivity fairly uniform at all heights in contrast to the decreased sensitivity in head and foot regions of a gamma-ray portal. Another difference is that neutron-detection-based detectors are less well collimated. As a result, the signal profile of a neutron source passing through a neutron-detection-based monitor is a little wider than a gamma-ray source profile would be in a gamma-ray portal. The useful monitoring time in a walk-through neutron portal may be slightly more than $1 \mathrm{~s}$; whereas in a gamma-ray portal, it might be slightly less.

\section{DETECTING NEUTRON SIGNALS}

The basic approach to monitoring is much the same in gamma-ray and neutron monitors. Backgrounds are measured, an alarm threshold is determined, and then monitoring measurements are compared with the alarm threshold to determine whether or not SNM is present during the passage of a pedestrian. However, there is one significant difference.
The low background count rates encountered in neutron-detection-based monitoring make a difference in the detection algorithms used in monitoring. Gamma-ray monitors can use a Gaussian approximation to Poisson counting statistics. As discussed in Sec. III, alarm thresholds can then be set a number of standard deviations above the expected background to fix the nuisance-alarm rate no matter what the background intensity may be. The same is not true for neutron backgrounds because they are much lower and the Gaussian approximation is no longer a good approximation to the Poisson distribution. The tail of the Gaussian approximation underpredicts the number of times that large counts are really encountered, and at low count rates the disagreement is very serious. Hence, an alarm threshold set a familiar number of standard deviations above background will give more nuisance alarms than expected. Instead, a threshold must be derived for each new background intensity to maintain any particular nuisance-alarm rate.

Generally, we need to establish the numerical value of the expected background during a monitoring measurement, then calculate the probability of the background plus a trial alarm-threshold increment being exceeded. This trial-and-error process involves summing the Poisson probabilities for each integral number above trial thresholds until the result gives an acceptable nuisance-alarm probability. Alternatively, a look-up table in microprocessor memory can be used as long as the alarm thresholds for possible background values have been predetermined.

Coop ${ }^{22}$ has used the look-up table for the Jomar JNC-17 neutron-portal-monitor controller, which is the only controller of its type presently available commercially. Other monitoring methods used in commercial gamma-ray portal monitors, such as the 
moving average, could be adapted for use at low counting rates. Alarm thresholds could be calculated from basic principles or from tabulated Poisson probabilities, for example Ref. 23, and then stored in microprocessor memory for retrieval when needed.

\section{NEUTRON DETECTOKS FOR NEUTRON-DETECTION-BASED SNM MONITORS}

As mentioned earlier, neutrons can be detected in the plastic scintillation detectors that are used for general-purpose SNM monitoring. However, the fact that plastic scintillators sense gamma rays gives them a relatively high counting rate from background, which limits their ability to detect low rates of neutron emission. Hence, the most sensitive neutron detectors are ones that sense only neutrons. Neutron proportional counters ${ }^{24}$ containing ${ }^{3} \mathrm{He}$ or $\mathrm{BF}_{3}$ have long been a part of nuclear safeguards, where they are routinely used for nondestructive assay of nuclear materials. Conventional safeguards instrument designs embed the proportional counters in polyethylene to moderate incident neutrons from fission and $(\alpha, n)$ reactions. Each detector moderator is designed to achieve a desired response for particular applications. For SNM monitoring, the desired response is unusual because the monitors must detect both bare and shielded SNM.

Designs for neutron detectors to detect both bare- and shielded-neutron sources stem from the DOE Nuclear Emergency Search Team (NEST) program. The NEST experiments comparing embedded proportional counters to other moderator designs led to using bare proportional counters (facing the neutron source) backed with an albedo layer of polyethylene in a portable instrument. ${ }^{25}$ Monte Carlo calculations by Atwater ${ }^{26}$ later optimized the design with a 5.08 -cm-thick moderating polyethylene backing that was scalloped to surround the proportional counters to half their diameter. A thin neutron entrance layer of polyethylene up to $1 \mathrm{~cm}$ thick was later found to improve the sensitivity of the optimum design for detecting bare sources in a vehicle-monitoring station. ${ }^{27}$ The thin entrance layer also diminishes the sensitivity for detecting polyethylene-shielded sources. Coop's Monte Carlo calculations to optimize a neutron-chamber detector for monitoring vehicles $^{20}$ arrived at essentially the same polyethylene dimensions for optimum detection of sources ranging from bare to moderately shielded (5-15 cm of polyethylene): a neutron entrance window $1.3 \mathrm{~cm}$ thick and moderating walls $5 \mathrm{~cm}$ thick.

The significant difference between both the NEST and vehicle-monitor detectors and the newer neutron chamber detectors is that the neutron chamber detectors use far fewer proportional counters per unit area but still achieve good detection efficiency. Atwater ${ }^{28}$ reports calculated total efficiencies for detecting a californium fission source moderated by a range of polyethylene thicknesses. The detector had 8 proportional counters containing $4 \mathrm{~A}_{\mathrm{g}}$ of ${ }^{3} \mathrm{He}$ and an area of $3800 \mathrm{~cm}^{2}$. Atwater's result for the $1.3-\mathrm{cm}$ polyethylene thickness used for the entrance layer in the vehicle monitor detectors corresponds to an intrinsic efficiency of $9.3 \%$. In comparison, a measured intrinsic efficiency of $4.2 \%$ for a neutron-chamber detector is reported in Ref. 29. The neutron-chamber detector was much larger, $29700-\mathrm{cm}^{2}$ area, and used 4 proportional counters that were twice as long and had one-half $\left(2 \mathrm{~A}_{\mathrm{s}}\right)$ the ${ }^{3} \mathrm{He}$ fill pressure. Although the two situations are not identical (source distance and ground effects are not the same), the neutron chamber seems to have almost half the efficiency of the vehicle monitor detector. But at the same time it has 7.8 times the area. Hence, the neutron- 
chamber detector will count 3.5 times as many neutrons from a distant source at a pror nrtional counter cost that is much less because of decreased gas pressure and fewer proporational counters.

The prototype neutron-detection-based pedestrian monitor developed at Los Alamos ${ }^{21}$ uses very simple detectors that contain a single proportional counte: : The detector (Fig. 11) is a hollow polyethylene chamber $(203 \mathrm{~cm}$ high and $71 \mathrm{~cm}$ wide) with optimum wall thicknesses. The chamber contains a single ${ }^{3} \mathrm{He}$ proportional counter $(5 \mathrm{~cm}$ in diameter and $182 \mathrm{~cm}$ long) that contains $2 \mathrm{~A}_{\mathrm{s}}$ of ${ }^{3} \mathrm{He}$.

\section{A PROTOTYPE NEUTRON-DETECTION-BASED PEDESTRIAN PORTAL}

Two of the detectors described above support a polyethylene neutron-reflector roof that forms a pedestrian portal (Fig. 1). The portal is relatively inexpensive, yet duplicates the performance of the one commercial prototype mentioned earlier. ${ }^{17}$ The signalconditioning electronics used in the prototype monitor are an ORTEC ${ }^{*} 142 \mathrm{PC}$ preamplifier; a Canberra $^{* *} 2015 \mathrm{~A}$ amplifier/single-channel analyzer, operating at a gain of 16 ; and a Canberra 3102 high-voltage supply operating at $1000 \mathrm{~V}$. The proportional counters are made by Reuter Stokes ${ }^{\dagger}$ and have activated charcoal linings. The monitor's control unit is a Jomar Systems JNC-17, which uses a remote communications module to inform a security inspector of the monitor's status through visual, audible, and voice synthesizer means. The control unit's operation can be changed by teletype to modify the monitor's performance

* EG\&r ORTEC, Oak Ridge, TN 37831-0985.

** Canver'a Industries Inc., Meriden, CT 06450.

$\dagger$ Reuter Stokes, Inc., Cleveland, OH 44128. over a range from walk-through to wait-in monitoring. The teletype can also record the monitor's operation, if necessary. Teletype records are intended to aid troubleshooting, but also provide an operational record of occupancies and alarms. The prototype monitor is now being commercialized. Jomar Systems has been making the controller for the Los Alamos prototype neutron-portal monitor as a

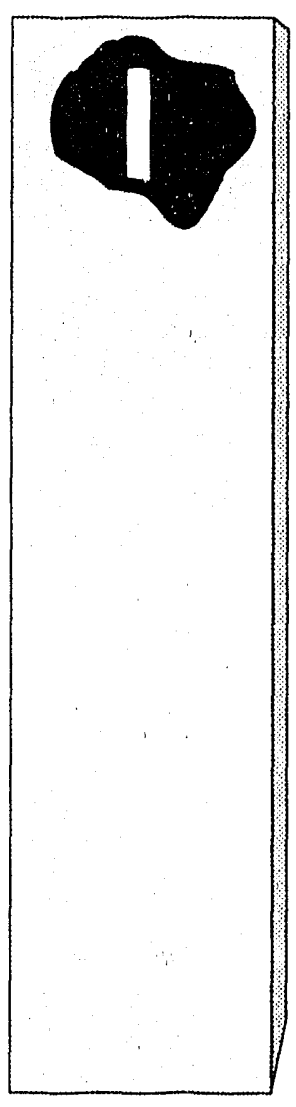

Fig. 11. The neutron-detection-based pedestrian monitor uses one of this type of neutron-chamber detector on each side of a pedestrian portal. 
commercial product for several years. Jomar and others are bidding on the initial

commercialization contract for the complete monitor, which differs from the prototype primarily in having the polyethylene-walled neutron-chamber detectors enclosed in a metallic envelope for safety reasons. The monitor is described further in Part 3. 


\section{PART 3}

\section{A CATALOG OF PEDESTRIAN SNM MONITORS}

This part updates the catalog section of the Applications Guide, since many of the monitors it described are now obsolete, and other new monitors have become commercially available.

Following the lead of the original Guide, new monitors are described here along with evaluation results when available. Business addresses and telephone numbers of each manufacturer are provided so that additional information can be requested, if desired.

Some of the monitors in the original catalog are still available; and some are now available in new commercial models described in the catalog sheets that follow. Entries still available in the original catalog (pages indicated) are listed below.

Hand-Held Monitors (p. 43): National Nuclear HM-3; Los Alamos Programmable Radiation Monitor (two commercial versions are described in this catalog); TSA Systems HHD -440 (revised to the HHD-440A described in this catalog).

Domestic Pedestrian Walk-Through Portals (pp. 44-51): National Nuclear DM-2; TSA Systems PM 310 (now model PM-600P); Los Alamos Pedestrian SNM Monitor (now Jomar JPM-22 described in this catalog).

Foreign Portal Monitors (pp. 53-55): All are still available.

Monitors that are no longer available:

Domestic Monitors: TSA Systems PM 203/101; IRT Corporation PRM 110 and PRM 120; Oak Ridge Y-12 Monitor; ICPP Monitor; Sandia Entry Control Portals. 


\section{HAND-HELD SNM RADIATION MONITORS}

\section{A. TSA Systems, Ltd. ${ }^{*}$ HHD-440A}

TSA Systems has revised its HHD-440 instrument to make it easier to produce. The manufacturer estimates that the revised instrument's operating time before charging increased from 7 to $\sim 16 \mathrm{~h}$ and claims that the HHD-440A is also easier for user facilities to calibrate. The basic properties of the instrument are unchanged: it still uses a large plastic scintillation detector (detects gamma rays and neutrons); and its detection logic is still the same, much like the logic used in automatic walk-through pedestrian monitors. The instrument continuously measures background intensity and maintains a timely alarm threshold. Monitoring is on demand, and the socurity inspector must press a membrane switch to enter the monitoring mode. This form of logic has permitted the HHD-440 instruments to be used temporarily as automatic portal monitors (at construction sites, for example) after only minor modification (offered by TSA as model HM-440 hallway monitor). The weight of the instrument is unchanged; it is still heavy, $3 \mathrm{~kg}$ $(6.5 \mathrm{lb})$, and is more suited for occasional use than steady use during an entire work shift.

\section{B. TSA Systems, Ltd. PRM-470}

This is a commercialized version of the Los Alamos Programmable Radiation Monitor that has somewhat evolved to meet customer needs. The most noticeable change is that membrane switches are used and only the basic monitoring switches are present. The instrument is lightweight, long operating, and available in two models: the 470 and 470P. The PRM-470 uses the original NaI(Tl) gamma-ray scintillator, and the PRM-470P has a plastic scintillation detector that senses both gamma rays and neutrons. Although the detection logic for these instruments is similar to that found in automatic portal monitors, it uses a shorter basic counting interval that is more appropriate for hand-monitoring. The weight of the PRM-470 is slightly more than $1 \mathrm{~kg}(2.4 \mathrm{lb})$, making it ideal for continuous use; the PRM-470P is a little heavier. Although these instruments are lighter and use smaller radiation deteciors than the HHD-440, their effectiveness for hand-held monitoring is not diminished.

\section{Jomar Systems, Inc. ${ }^{* *} \mathrm{JHH}^{\circ 20}$}

This instrument is also a comnercialized version of the Los Alamos Programmable Radiation Monitor but one that follows more closely the original Los Alamos specification and has a measurement capability in addition to being a hand-held monitor. The instrument is lightweight, long operating, and is also available in two models: the $\mathrm{JHH}-20$ and JHH-21. The JHH-20 uses the original NaI(Tl) gamma-ray scintillator, and the $\mathrm{JHH}-21$ uses a plastic scintillation detector that senses both gamma rays and neutrons. In its search mode, the instrument's detection logic uses the original thumbwheel switch to alter the alarm threshold to accommodate changing background intensity. This gives the instrument adequate sensitivity for detecting 10-g HEU up to a background intensity of $\sim 0.25 \mathrm{mR} / \mathrm{h}$. When measuring, the thumbwheel sets a counting time that allows the

\footnotetext{
* TSA Systems, Ltd., 1820 Delaware Place, Longmont, CO 80501 (303) 651-6147.

** Jomar Systems, Inc., 110 Eastgate Dr., Los Alamos, NM $87544 \quad$ (505)662-9811.
} 
instrument to more accurately measure radiation intensity. This permits the instrument to verify that containers have less than a prescribed amount of SNM. The weight of the JHH-20 is $1.6 \mathrm{~kg}(3.6 \mathrm{lb})$, making it suitable for continuous use; the JHH-21 is a little heavier.

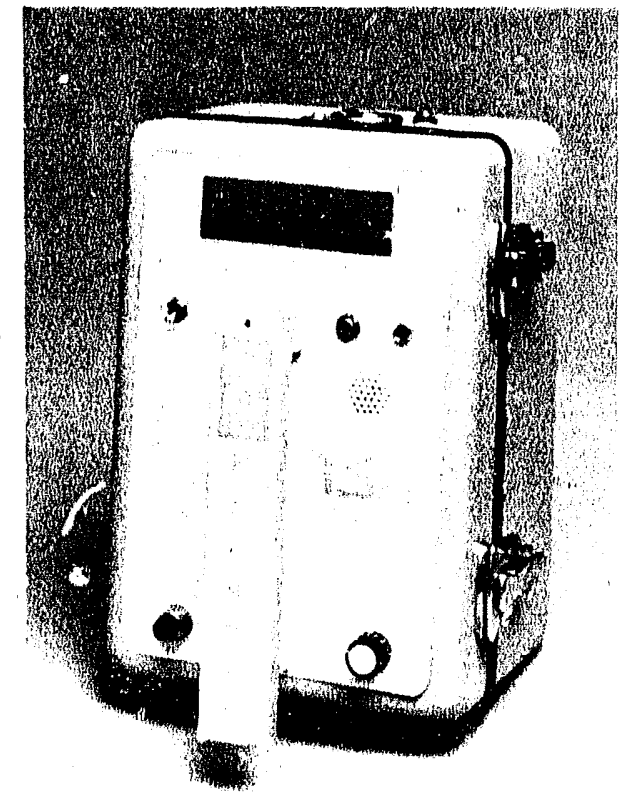

TSA HHD.440A

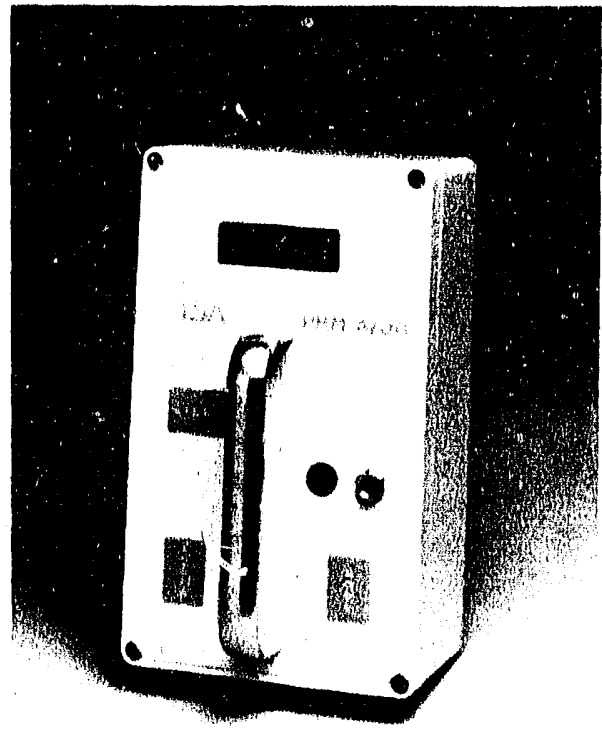

TSA PRM-470A

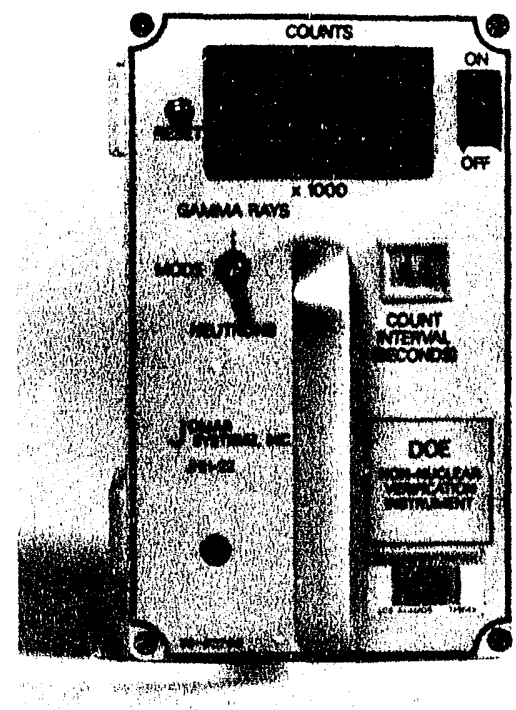

Jomar JHH-22 


\section{TSA SYSTEMS, LTD., ${ }^{*}$ PM-700 SERIES, WALK-THROUGH PORTAL MONITORS}

The TSA PM-700 series of monitors places

the signal-conditioning and microprocessor

electronics in the same cabinets that form a portal and contain the plastic scintillators used for radiation detection. As a result, the monitors are relatively compact and can be very readily adapted to different

circumstances, such as different portal widths. This type of monitor construction is made possible by using low-power electronics operating from trickle-charged batteries, which greatly reduces the amount of heat that would otherwise be generated by conventional NIM electronics. Battery-powered operation offers about $12 \mathrm{~h}$ of continuous operation if line power fails. The modular approach used in this series of monitors permits the manufacturer to cover a great deal of variation in applications. Different size detectors are readily accommodated, and each detector in a pair can be monitored independently. The signals from a pair of cabinets also can be summed for increased sensitivity. Different control units are available for special applications, such as monitoring individual detector signals to increase sensitivity for detecting radiation from body surfaces (Model PM.700HS).

Los Alamos evaluated the basic PM-700, which has 4 large plastic scintillators, each $25 \mathrm{~cm}$ wide, $91 \mathrm{~cm}$ long, and $3.8 \mathrm{~cm}$ thick. The monitor operated as a Category II walkthrough portal (79 $\mathrm{cm}$ wide), with a nuisance-alarm rate of $1 / 1220$ pedestrian passages in a $25-\mu \mathrm{R} / \mathrm{h}$ background. The potential for better HEU sensitivity was limited by noise levels in the battery-powered electronics, which prevented setting the lowest possible detector bias level. This shortcoming does not influence its use for plutonium monitoring, an application for which it is well suited. The PM-700HS has been evaluated at the Savannah River Site.

Another of the TSA 700 series, the PM-701, has smaller (15- by 79-cm) detectors and proportionally smaller detector cabinets that still contain the electronics. This version has not been evaluated, but should achieve at least Category I performance in a laboratory evaluation as a walk-through portal at the spacing, nuisance-alarm rate, and background intensity mentioned above. Oak Ridge Y-12 plant has evaluated the PM-701 monitors.

A unique monitor that is also part of the 700 series is the PRS-1, or portable radiation scanner; it provides monitoring support when a permanently installed monitor is being repaired. The PRS-1 is designed for high radiation areas, and, as a result, it has very heavy radiation shielding that limits its portability. It has only one detector of the type used in the PM-701 monitor, which makes it less sensitive for monitoring the upper torso. The PRS-1 is most useful for monitoring plutonium. Rocky Flats uses the PRS-1 as a temporary, short-term monitor.

Los Alamos has published a calibration and testing manual for the TSA PM-700 series monitors. ${ }^{30}$ The Laboratory is also examining the electronics design used in the PM-700 series to see if the noise levels can be reduced to enchance HEU monitoring.

* TSA Systems, Ltd., 1820 Delaware Place, Longmont, CO 80501 (303) 651-6147. 


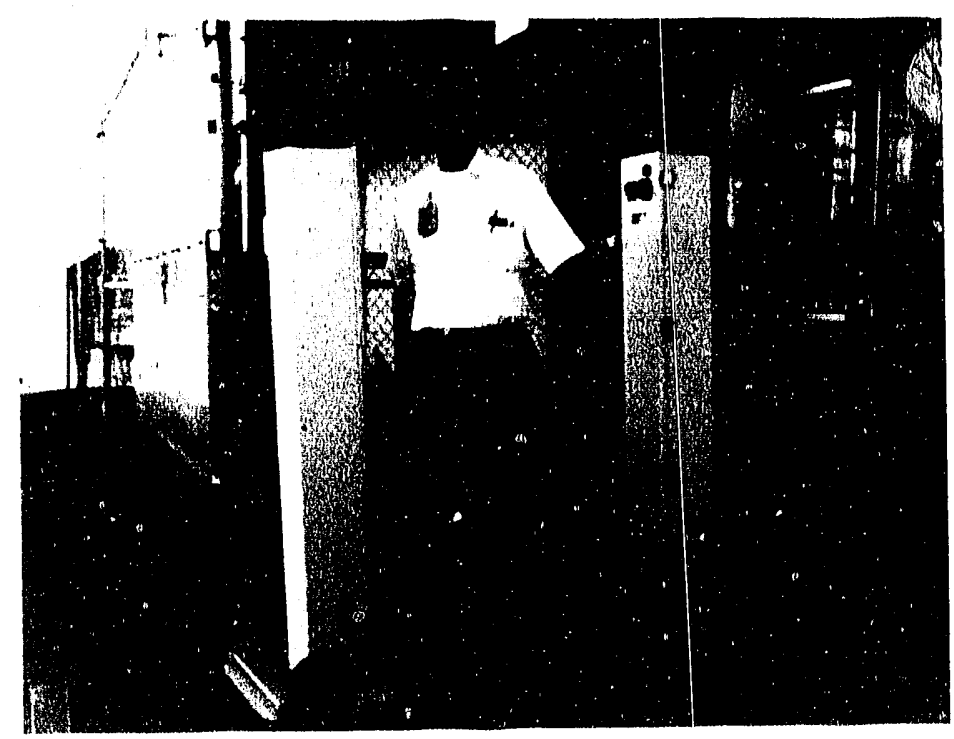

TSA PRS-1

TSA PM-70I
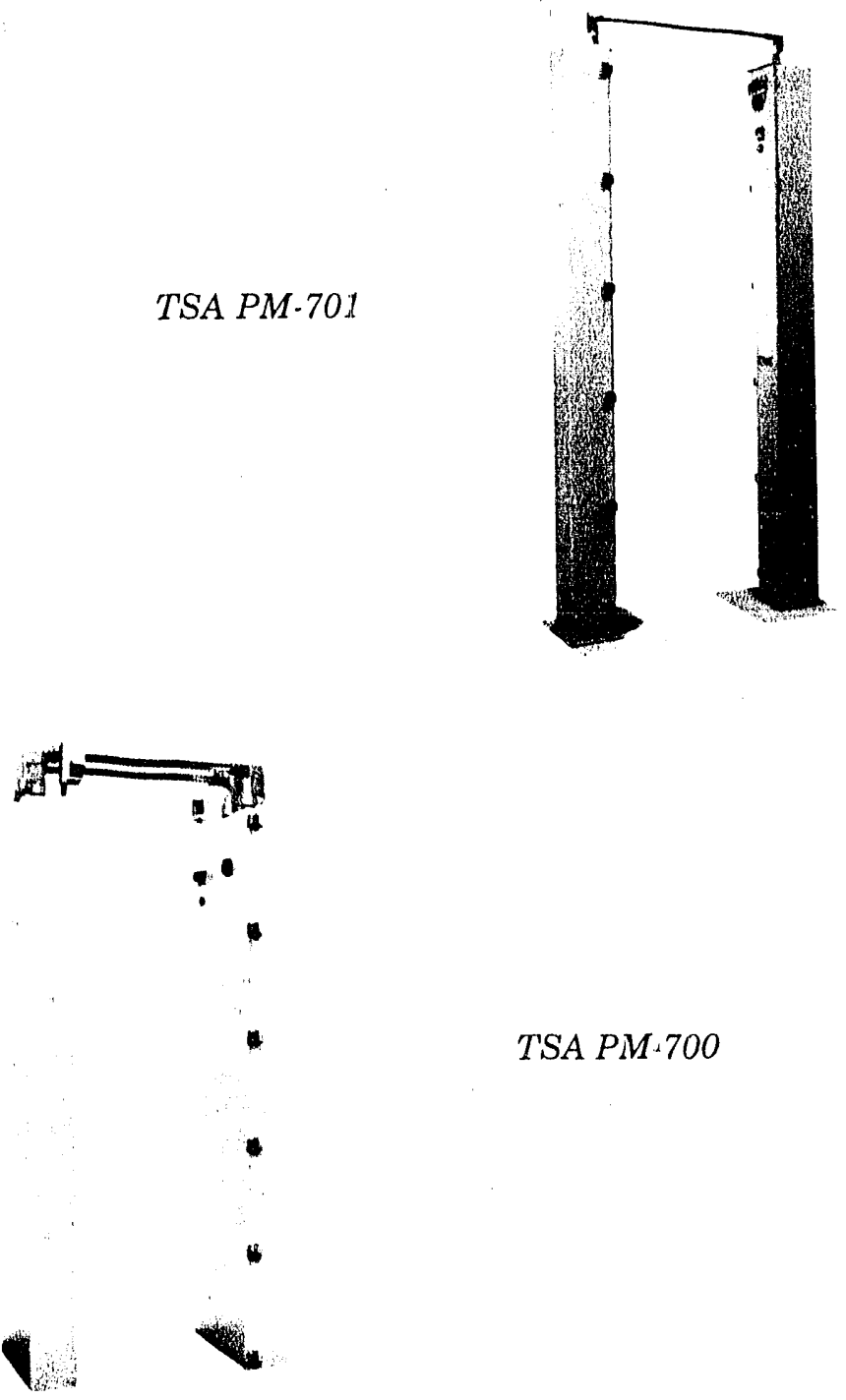

TSA PM 700 


\section{JOMAR SYSTEMS ${ }^{*}$ MODEL JPM-22 WALK-THROUGH OR WAIT-IN MONITOR}

The Jomar JPM-22 is a monitor developed at Los Alamos for walk-through or wait-in operation, and it is presently being routinely used for both applications. Los Alamos and Portsmouth have the walk-through version, and Sandia uses two of the monitors in monitoring booths.

The monitor uses nuclear instrument modules for its signal-conditioning electronics, and noise levels are low enough for the efficient detection of HEU or plutonium with its standard 15- by $79-\mathrm{cm}$ or other-size plastic scintillation detectors. The resuits from laboratory evaluation of the JPM-22 in walk-through operation (portal width $74 \mathrm{~cm}$ ) place it in Category II at a nuisance-alarm rate of $1 / 2076$ passages in an $18-\mu \mathrm{R} / \mathrm{h}$ background. In wait-in operation (2-s count), the monitor could achieve Category III performance as long as the occupant faced the radiation detectors to reduce body shielding of the test source.

A new capability introduced in this monitor is teletype input and output of operating information. Operating parameters are stored in electrically alterable memory. The monitor can be configured for walk-through or wait-in operation by teletype. For walk-through operation, parameters can be set by teletype for passage speeds ranging from a slow walk to vehicle speeds. The parameters adjust the number and duration of nonitoring measurements and the amount of preoccupancy data that is used for monitoring.
The monitor also has a selectable monitoring-with-diagnostics mode to print results of statistical signal analysis, the number of occupancies, and the number of alarms during operation.

The teletype can also select wait-in operation, in which case a person stands in the monitor until signaled to leave (an alarm sounds if he leaves early). A sequential detection scheme minimizes the monitoring time, and the pedestrian leaves as soon as a decision is reached, rather than having to stay for a fixed period.

Los Alamos has also published a calibration manual for the JPM-22 monitor; for more information see Ref. 31.

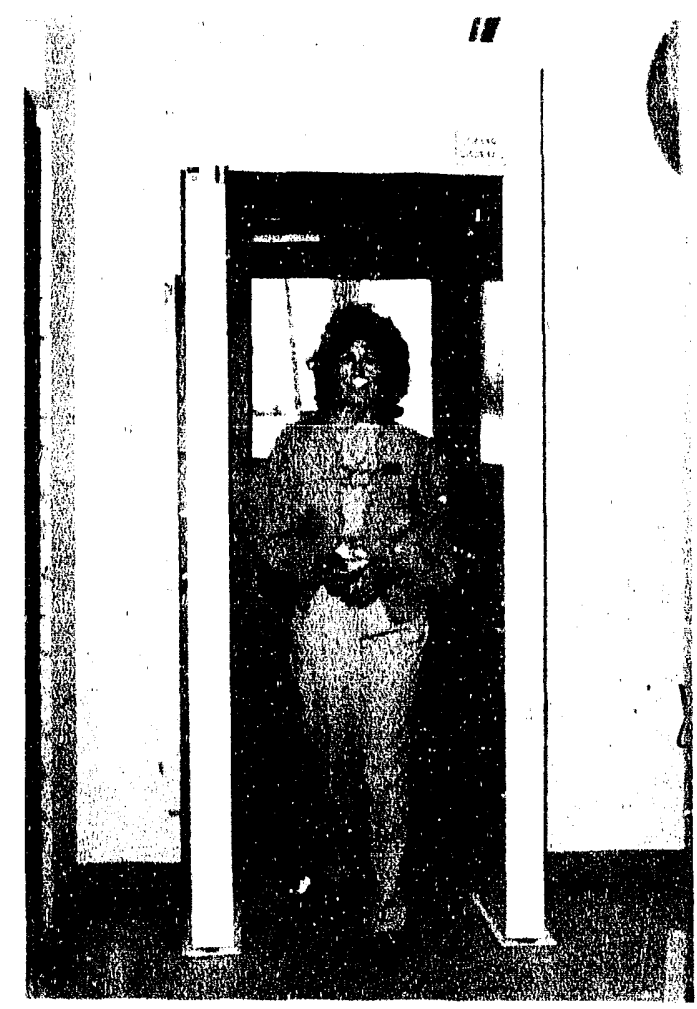

Jomar JPM-22

* Jomar Systems, Inc., 110 Eastgate Dr., Los Alamos, NM 87544 (505) 662-9811. 


\section{CONTAMINATION MONITORS OFFERED FOR USE AS SNM MONITORS}

Two contamination portal monitors that use large plastic scintillation detectors have been offered for evaluation as SNM monitors. The difference between the applications is that theft involves hidden SNM, whereas contamination is usually inadvertent accumulation of radioactive material on body surfaces. A contamination monitor may analyze signals frois zach radiation detector separately to localize the source; it may also analyze the sum of all signals to look for distributed, low-intensity contamination. Head and foot detectors are routinely used in addition to the side detectors that form a portal. In contrast, SNM monitors usually sum all signals to obtain the highest possible sensitivity in the low-sensitivity regions that are farthest from the detectors.

As a result of monitoring as many as seven signals instead of one, contamination monitors must use somewhat higher alarm thresholds than SNM monitors to achieve an acceptable nuisance-alarm rate. High sensitivity is obtained for sources near the detectors at the cost of somewhat lower sensitivity for centrally located sources. Other measurcs taken to flatten detector response or to maintain a constant detection sensitivity no matter what the counting time can also diminish sensitivity below that achieved in SNM monitors.

The DM-ê, manufactured by National Nuclear Corp., ${ }^{*}$ has been evaluated in the laboratory; it achieved Category II performance as a walk-through monitor and Category III performance as a wait-in monitor (3-s count).
The nuisance alarm rate in walk-through operation was $1 / 2600$ passages; the portal width was $61 \mathrm{~cm}$; and the background intensity was $18 \mu \mathrm{R} / \mathrm{h}$. Detector area was about double that of similarly performing SNM monitors. Apparently a tailored detector response used for contamination monitoring reduces sensitivity for SNM monitoring. Detector signals in the DM-60 cannot be viewed during calibration, but computer programs are included for adjusting detector bias levels and energy windows. The documentation included with the monitor was both excellent and necessary for operation. Several repairs were needed during the evaluation, and, in one case, an electrical hazard inadvertently discovered in the monitor's wire-crowded electronics cabinet caused additional damage.

The TSA Systems SPM-904 has been evaluated in the laboratory and achieved Category II performance as a wait-in monitor, its only mode of operation. The nuisance-alarm rate was $1 / 1100$ passages; the portal width was $61 \mathrm{~cm}$; and the background intensity was $18 \mu \mathrm{R} / \mathrm{h}$. Monitoring time was set at $1 \mathrm{~s}$; and the monitoring algorithm does not increase sensitivity with longer monitoring times. Although the monitor needed only slight adjustments before it operated, one adjustment required removing 4 screws and dismounting an electronics cabinet to open it to reach the adjustment. The manual contained many errors, and the manufacturer later reported errors in the software; however, the manufacturer is continuing development to make the monitor more effective.

* National Nuclear Corp., 1904 Colony St. Mountain View, CA 94043 (415) 962-9220. 
Eberline ${ }^{*}$ has just begun to market a monitor in this category, the PM7. This monitor has not been evaluated.

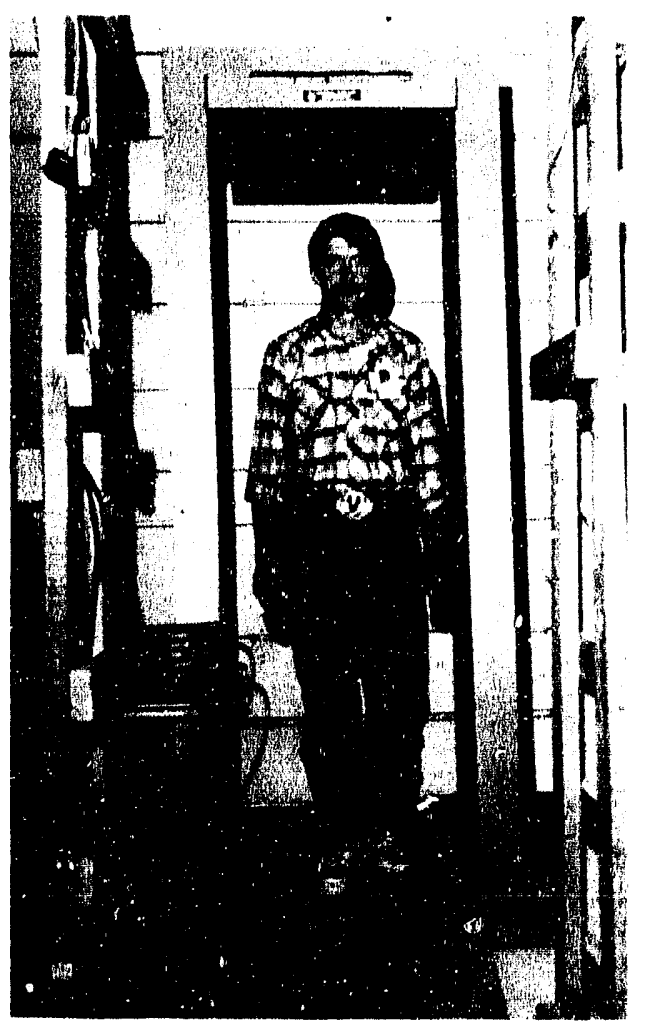

National Nuclear DM-60

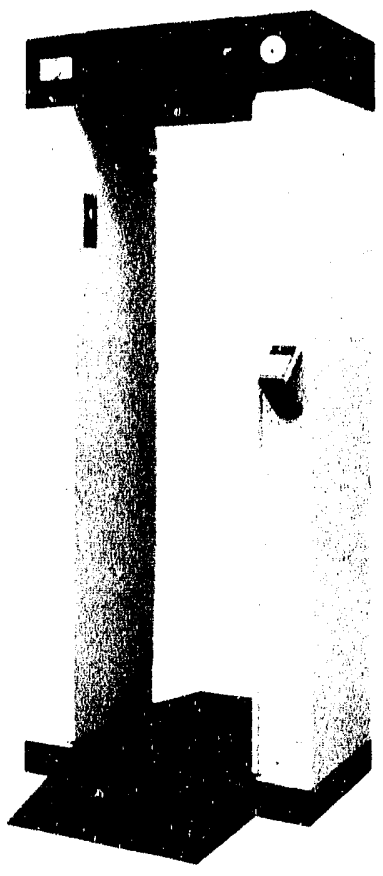

TSA SPM-904

Eberline, P.O. Box 2108, Santa Fe, NM 87504-2108 (505) 471-3232. 


\section{NEUTRON-DETECTION-BASED PEDESTRIAN MONITOR}

The Los Alamos-developed, neutrondetection-based pedestrian monitor is presently being commercialized. The monitor is insensitive to gamma rays and detects only neutrons. As a result, it has low background and good sensitivity for the low neutronemission rates from low-burnup plutonium. On the other hand, it is completely insensitive to forms of SNM that do not emit neutrons. This monitor will likely replace the need for metal detectors to detect metallic shielding of plutonium because neutrons readily penetrate metallic shields. Where highest sensitivity for both shielded and unshielded plutonium is required, the neutron portal would be used together with a gamma-ray portal.

The monitor has not been commercially produced, but both TSA Systems ${ }^{*}$ and Jomar Systems ${ }^{* *}$ have offered to produce monitors according to the Los Alamos specification. Jomar already produces the commercially available control unit for the monitor: the JNC-17 controller. Los Alamos has built two prototype detector units, one owned and evaluated by Westinghouse Savannah River Site and the other under evaluation at Westinghouse-Hanford.

The key to developing this monitor is its low-cost detector design. A hollow polyethylene chamber moderates neutrons from spontaneous fission in plutonium. Well-moderated neutrons can bounce between chamber walls until they are absorbed. One ${ }^{3} \mathrm{He}$ proportional counter at the center of the detector chamber has a good chance to detect the moderated neutrons. This detector design achieves half the sensitivity at one-tenth the cost of alternative detectors.

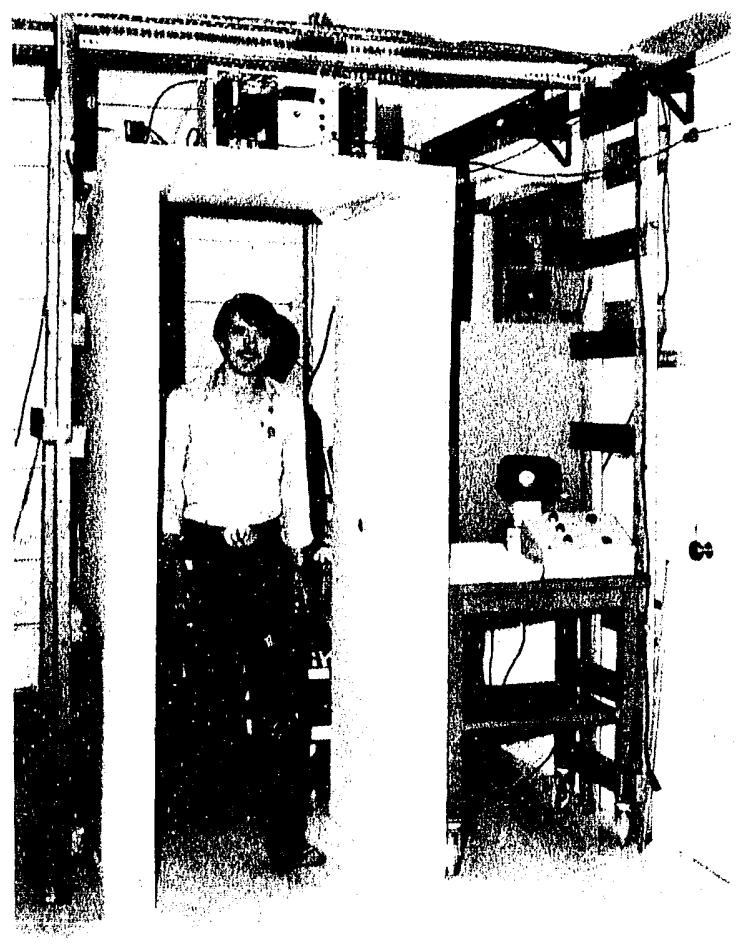

Los Alamos Neutron Pedestrian Monitor

\section{REFERENCES}

1. P. E. Fehlau, "An Applications Guide to Pedestrian SNM Monitors," Los Alamos National Laboratory report LA-10633-MS (February 1986).

2. ASTM Standard C1112-88, "Standard Guide for Application of Radiation Monitors to the Control and Physical Security of Special Nuclear Material," published by the American Society for Testing and Materials, 1916 Race St., Philadelphia, PA 19103.

\footnotetext{
* TSA Systems, Ltd., 1820 Delaware Place, Longmont, CO 80501 (303) 651-6147.

** Jomar Systems, Inc., 110 Eastgate Dr., Los Alamos, NM 87544 (505) 662-9811.
} 
3. M. Edward Anderson and John F. Lemming, "Selected Measurement Data for Plutonium and Uranium," Mound report MLM-3009 (November 1982).

4. E. Storm and H. Israel, "Photon Cross Sections from $1 \mathrm{keV}$ to $100 \mathrm{MeV}$ for Elements $Z=1$ to $Z=100$," Nuclear Data Tables; Vol. 7, No. 6, June 1970.

5. N. Ensslin, et al., "Savannah River/HEU Assay Instrumentation, Low Density Waste System," in "Safeguards and Security Progress Report, January-December 1985," D. B. Smith, Comp., Los Alamos National Laboratory report LA-10787-PR (March 1987), p. 34.

6. N. A. Webster, "Rapid Monitoring of Trash for Radioactive Content," Proceedings of the 22nd Midyear Topical Meeting of the Health Physics Society on Instrumentation, San Antonio, Texas, December 4-8, 1988, p.118.

7. J. A. Guticrrez, "A Portable Radionuclide Identification System to Enhance Security in Nuclear Materials Processing Plants," Nucl. Mater. Manage. XVIII (Proc. Issue), p. 43 (July 1989).

8. P. E. Fehlau, "Rugged, Lightweight, and Long-Operating Hand-Held Instruments for Neutron and Gamma-Ray Verification Measurements," Proceedings of the 22nd Midyear Topical Meeting of the Health Physics Society on Instrumentation, San Antonio, Texas, December 4-8, 1988. Los Alamos National Laboratory document LA-UR-88-2780 (December 1988).

9. P. E. Fehlau, J. C. Pratt, J. T. Markin, and T. Scurry, Jr., "Smarter Radiation Monitors for Safeguards and Security," Nucl. Mater.

Manage. XII (Proc. Issue), p. 122 ( July 1983).
10. C. N. Henry and J. C. Pratt, "A New Containment and Surveillance Portal Monitor Data Analysis Methoc," Proc. 1st Annual ESARDA Symp. Safeguards and Nucl. Mater. Manage., Brussels, Belgium, April 25-27, 1979, European Safeguards Research and Development Association report ESARDA 10, p. 126 (1979).

11. B. H. Erkilla, "Automatic Material Identifier," Nucl. Mater. Manage. XIII (Proc. Issue), pp. 154-157 (July 1984).

12. J. K. Sprinkle, Jr., "A Confirmatory Measurement Technique for Highly Enriched Uranium," Los Alamos National Laboratory report LA-11021-MS (July 1987).

13. M. W. Johnson and K. B. Butterfield, " $i$. Intelligent Portal Monitor for Fast Suppression of False Positives Due to Radiopharmaceuticals," Nucl. Mater. Manage. XIV (Proc. Issue), pp. 466-472 (July 1.985.)

14. H. O. Menlove, T. L. Atwell, and A. Ramalho, "Upgrading of SNAP Neutron Detector, SNAP-II," in "Nuclear Safeguards Research and Development Program Status Report, September-December 1975," J. L. Sapir, Ed., Los Alamos Scientific Laboratory report LA-6316-PR, pp. 5-6 (April 1976).

15. J. T. Caldwell, H. F. Atwater, W. Bernard, J. M. Bieri, and E. R. Shunk, "A Large Vehicle Portal Monitor for Perimeter Safeguards Applications," Proc. 1st Annual ESARDA Symp. Safeguards and Nucl. Mater. Manage., Brussels, Belgium, April 25-27, 1979, European Safeguards Research and Development Association report ESARDA 10, p. 122 (1979).

16. P. E. Fehlau and Eaton, M. J., "Passive Nuclear Material Detection in a Personnel 
Portal," National Bureau of Standards Special Publication 582, 365 (1980).

17. S. J. Friesenhahn, H. J. Weber, and C. A. Preskitt, "Portal Neutron Monitor," Nucl. Mater. Manage. X (Proc. Issue), p. 272 (1981).

18. R. J. Riley and D. Williams, "Recent Developments in Doorway Monitors," Proc. 3rd ESARDA Symp. Safeguards and Nuc. Mater. Manage., European Safeguards Research and Development Association report ESARDA 13 (1981).

19. J. T. Caldwèll, H. F. Atwater, and E. R. Shunk, "High Density Waste Assay: Large Crate Counting Via Passive Neutron Counting," in "The LASL Radioactive Waste Assay Instrumentation Development Program," J. Umbarger, Ed., Los Alamos Scientific Laboratory report LA-8336-MS (1980).

20. K. L. Coop, P. E. Fehlau, and H. F. Atwater, "A Neutron Portal Monitor for Vehicles," Nucl. Mater. Manage. XVI (Proc. Issue), pp. 454-460 (1987).

21. P. E. Fehlau, "A Low-Cost Safeguards Pedestrian Portal Monitor Using Chamber Neutron Detectors," Proc. 9th Ann. ESARDA Symp. Safeguards Nuc. Mater. Manage., London, England, May 12-14, 1987, European Safeguards Research and Development Association report ESARDA 21, pp. 77-80.

22. K. L. Coop, "Monte Carlo Simulation of the Sequential Probability Ratio Test for Radiation Monitoring," IEEE Trans, Nucl. Sci. NS-32, 934 (1985).

23. General Electric Co., Tables of the Individual and Cumulative Terms of the Poisson Distribution, (D. Van Nostrand, Co., Princeton, MA 1962).
24. T. W. Crane and M. P. Baker, "Neutron Detectors," in "Passive Nondestructive Assay of Nuclear Material," T. D. Reilly, N. Ensslin, and H. A. Smith, Eds., U.S. Nuclear Regulatory Commission contractor report NUREG/CR-5550, to be published.

25. E. J. Dowdy, C. N. Henry, R. D. Hastings, and S. W. France, "Neutron Detector Suitcase for the Nuclear Emergency Search Team," Los Alamos Scientific Laboratory report LA-7108 (February 1978).

26. H. F. Atwater, "Effect of Moderator Thickness on Neutron Detector Efficiency," Los Alamos Scientific Laboratory memorandum R-2-76-395 (June 25, 1976).

27. P. E. Fehlau, R. Payne, R. Hemphill, R. Zirkle, and J. Landt, "Vehicle SNM Monitor Study," in "Nuclear Safeguards Research and Development Program Status Report, May-August 1978," S. D. Gardner, Ed., Los Alamos Scientific Laboratory report LA-7616-PR (April 1979).

28. H. F. Atwater, "Calculated Efficiency of the Old Style Neutron Multiplication Detector Pods," Los Alamos National Laboratory memorandum Q-2-81-260 (October 23, 1981).

29. P. E. Fehlau, "An Applications Guide to Vehicle SNM Monitors," Los Alamos National Laboratory report LA-10912-MS (March 1987).

30. Paul E. Fehlau, "Calibrating the TSA Systems VM-250 SNM Portal Monitor," Los Alamos National Laboratory report LA-11871-M (July 1990).

31. Paul E. Fehlau, "Calibrating the Jomar JPM-22 Pedestrian SNM Monitor," Los Alamos National Laboratory report LA-11643-M (August 1989). 


\section{ACKNOWLEDGMENTS}

I thank the members of the Advanced Nuclear Technology Group who have assisted with developing and evaluating various radiation monitors for Nuclear Safeguards applications. I am also indebted to manufacturers who have provided equipment for evaluation and to my colleagues at many DOE facilities who have kept me in touch with the state of in-plant SNM monitoring. Thanks also to everyone who has helped with the standards development process in the ASTM. 


\section{APPENDIX A \\ A SYNOPSIS OF NUISANCE-ALARM TESTING FROM DRAFT ASTM STANDARDS*}

\section{INTRODUCTION}

Routine operational evaluation of pedestrian SNM monitors examines nuisance-alarm records for each monitor in addition to detection sensitivity. The routine operational evaluation is intended to reassure the plant operator, and his regulatory agency, that the monitor is performing as expected during routine operation. The nuisance-alarm probability during the period since the monitor was last maintained, calibrated, or evaluated is determined using the number of alarms and pedestrian passages from records kept during routine monitor use.

\section{NUISANCE-ALARM DATA}

Hand-written alarm logs or records from the monitor's control unit can provide total alarms from which allowed alarms from performance testing or legitimate passage of radioactive material must be subtracted. Total pedestrian passages can be estimated from operating logs or recorded information from the monitor's control unit.

Nuisance alarms must be recorded along with the total number of passages through the monitor. Recording can be a continuous process when an inspector keeps a written record of alarms and passages in a log book, or when the monitor control unit automatically records alarms and passages. When automatic recording of passages is not possible, carefully estimating the number of passages per day may suffice.

\section{DATA ANALYSIS}

The nuisance-alarm probability per passage is the total number of alarms divided by the total number of passages ( $x 100$ to express in percent). Monitors often have nuisance-alarm probabilities in the range of $0.025 \%$ to $0.1 \%$ per passage when properly operating and without interference from facility operation. The nuisance-alarm rate is the number of passages divided by the number of alarms. The corresponding rate range to the probabilities mentioned above is 1 alarm per 4000 passages to 1 alarm per 1000 passages.

\section{INTERPRETATION OF RESULTS}

Consistent nuisance-alarm rates high enough to cause a lack of credibility for a monitor's alarms must be investigated and

* The synopsis is based on two ASTM drafts: the "Standard Guide to In-Plant Performance Evaluation of Automatic Pedestrian SNM Monitors" and the "Standard Guide to Laboratory Evaluatuion of Automatic Pedestrian SNM Monitor Performance." 
corrected. Begin investigating by checking the monitor's calibration. Refer to the

manufacturer's recommended procedure, local procedures, and to the ASTM guide to calibrating pedestrian SNM monitors. If the problern persists, then recording the monitor's count rate on a strip chart or data logger may disclose interference from sources of radiation or, perhaps, intermittent misoperation of the portal. Radiation interference may be reduced by shielding its source; causes of intermittent misoperation can usually be found and repaired once they are known to exist.
Examples of nuisance-alarm rates from published guidelines for acceptable performance range from a low of 1 per 8 -h operating shift, which is imprecise but, for example, would correspond to a nuisancealarm probability per passage of $0.034 \%$ (1 nuisance alarm per 2880 passages) if a person passed through the monitor every $10 \mathrm{~s}$, to a high rate of 1 per 1000 passages, which corresponds to a nuisance-alarm probability per passage of $0.1 \%$. 


\section{APPENDIX B \\ A SYNOPSIS OF TESTING AND CALIBRATION FROM ASTM STANDARDS*}

\section{INSTALLATION TESTS}

A monitor should be calibrated and then tested with SNM at the time of installation. Written records of calibration, including all parameter settings and observations, should be kept on file to aid any future repair and troubleshooting effort and to provide evidence for a well-run maintenance program.

\section{DAILY TESTS}

Daily testing to verify that a monitor is in good working order and is capable of reporting an alarm often can be done by protective force inspectors, either once a day or at the start of each work shift. If repair is needed, a hand-held monitor or portable monitor can be used in the interim. An isotopic source such as ${ }^{137} \mathrm{Cs}$, normally used for calibration, or a ${ }^{133} \mathrm{Ba}$ with $3.7 \times 10^{4}$ to $1.1 \times 10^{5} \mathrm{~Bq}(1-$ to $3-\mu \mathrm{Ci})$ activity, would be suitable for the purpose. Written records of daily tests signed by the security inspector will provide good supporting documentation.

\section{ROUTINE OPERATIONAL TESTS}

At MAA boundaries, where an SNM test source can be stored near the monitors, testing with SNM is usually practical, and a schedule of testing with SNM by authorized personnel can be established to verify that the monitors meet the sensitivity required by the facility physical protection plan. Testing with SNM can be at weekly, monthly or longer intervals, but should not exceed 3-month intervals.

At protected-area boundaries where SNM is not readily available, isotopic source tests can substitute for SNM source tests, particularly if testing is more frequent than 3-month intervals. Barium-133 is a substitute source suggested in Table D-I (App. D), which lists an appropriate source activity for pedestrian monitors in each performance category.

\section{PERIODIC CALIBRATION CHECK AND TESTING}

At 3-month intervals, each monitor's calibration should be checked and then the monitor should be tested with SNM. Testing and recalibration as needed should also follow

* Based on information from ASTM Standard C1112-88, "Standard Guide for Application of Radiation Monitors to the Control and Physical Security of Special Nuclear Material," published by the American Society for Testing and Materials, 1916 Race St., Philadelphia, PA 19103. 
any repair, even repairs that are not expected to affect performance. Moving an automatic monitor to another location also calls for recalibration and testing.

Monitor calibration and maintenance are easiest if the manufacturer provides designated and protected (but readily accessible for maintenance) test points, test signal connectors, and adjustments, located externally, which provide everything that needs to be observed or adjusted during calibration. A clear, complete, and easily read calibration and maintenance manual is essential for proper monitor upkeep.

Test procedures and test sources for monitors are described in a series of ASTM standards. Test sources may be standard forms of SNM, process materials, or alternative soutces. In the case of plutonium, a thin cadmium absorber removes $60-\mathrm{keV}$ gamma rays from ${ }^{241} \mathrm{Am}$ that builds up over time. 


\section{APPENDIX C \\ A SYNOPSIS ON APPLYING SNM MONITORS FROM ASTM STANDARDS ${ }^{*}$}

\section{GENERAL RULES}

Pedestrian and vehicle monitors should be used at the boundary of MAAs or protected areas as required by a facility physical protection plan for SNM. Monitor locations should be in areas of minimum background and minimum background variation. The monitor's detectors should be collimated with lead shielding to limit their view to the area that will be occupied during monitoring. Traffic flow speed should match a monitor's optimal performance speed (easily adjustable in some monitors). An extended measurement time in a monitor located where a person must stand during identification and badge inspection for exit clearance can improve the monitor's sensitivity over walk-through monitoring. Turnstiles can slow pedestrians and speed bumps can slow vehicles to increase the available monitoring time in a portal. Automatic monitors are most reliable but hand-held monitors adapt more easily to high and variable background. In some cases, hand-held monitors can more closely approach SNM, increasing the SNM signal relative to background and making it easier to detect.

\section{BACKGROUND AND OCCUPANCY}

Background updating should be on push-button command in hand-held monitors and continuous in unoccupied automatic monitors. Background measurement times should be at least 20 times as long as monitoring measurement periods to minimize the influence of background precision on a monitoi's statistical nuisance-alarm rate. But shorter background measurements may occasionally be necessary to cope with a variable background. Occupancy sensors (visible or infrared light beam, for example) should be used to inform automatic monitors when to monitor (occupied) and when to measure background (unoccupied).

Ideally, only one pedestrian at a time should be in the monitoring area to keep bystanders from altering the true background, providing shielding, or causing confusion about which person caused an alarm. Where prevailing circumstances allow multiple occupancy, photographic or video records of monitor occupants triggered by an alarm may help find the cause.

* Based on information from ASTM Standard C1112-88, "Standard Guide for Application of Radiation Monitors to the Control and Physical Security of Special Nuclear Material," published by the American Society for Testing and Materials, 1916 Race St., Philadelphia, PA 19103. 
Background limit alarms should be provided in automatic monitors. Backgrounds outside the limits may indicate a need for repair or simply an unusually high background that lowers the monitor's sensitivity enough that hand-held monitoring is needed. An upper limit should be set at the point that the sensitivity becomes inadequate. For example, if sensitivity is insufficient above a background of $35 \mu \mathrm{R} / \mathrm{l}(9 \mathrm{nC} / \mathrm{kg} \mathrm{h}$ or $2.5 \mathrm{pA} / \mathrm{kg}$ ) and the normal background is $25 \mu \mathrm{R} / \mathrm{h}$ and produces 5000 counts/s in the monitor, its upper limit would be set at 7000 counts/s. The same monitor operated in a $10-\mu \mathrm{R} / \mathrm{h}$ background displays a lower count rate but has the same upper limit. Lower limits are set to detect one, non-functioning detector. In the example above, with 4 detectors, the lower limit would be set at 3900 counts $/ \mathrm{s}$ at a $25-\mu \mathrm{R} / \mathrm{h}$ background and 1600 counts/s at a $10-\mu \mathrm{R} / \mathrm{h}$ background.

Background alarms are signaled with indicator lamps, and in some cases, the monitor is taken out of service, except for making a vocal announcement to hand-monitor each time the monitor is occupied.

\section{TAMPER RESISTANCE}

All monitor wiring, controls, and adjustments should be protected from harm and accidental or unauthorized changes.

Wiring can be protected in conduit or supervised to detect tampering. Separate information and control modules having the necessary indicators and switches for security inspectors can be provided. Tamper switches can be used on all cabinets containing monitor or occupancy-sensor hardware to detect inadvertent or unauthorized access to the monitor.

\section{BYPASS BARRIERS AND AUDIBLE SIGNALS}

Bypass barriers for portal monitors should be used to prevent $\mathrm{p} \varepsilon$ sage outside the monitor's sensitive region. Barrier panels are used for walk-through pedestrian monitors, and in monitoring booths, the booth walls prevent bypass.

In automatic monitors, a chime or other pleasant sound can inform the inspector that an occupant has been sensed and is being monitored, a positive indication that the monitor is operating. Where traffic flow is high, making the chime a nuisance, a readily visible indicator lamp may be more appropriate.

A sound that readily demands attention should be used to announce alarms. Visual alarm signals also help. But the alarm announcement should not be severe enough to unnecessarily distract the inspector at a time when he should closely observe the pedestrian causing the alarm. 


\section{APPENDIX D \\ A SYNOPSIS OF IN-PLANT EVALUATION FROM DRAFT ASTM STANDARDS*}

\section{INTRODUCTION}

In-plant performance evaluation takes place at intervals ranging from weekly to once every 3 months and may examine both a monitor's nuisance-alarm record and its' detection sensitivity for a particular SNM or alternative test source. In-plant evaluation is fairly rapid, takes place in the routine operating environment, and verifies that a monitor is operating as expected or discloses that it is not and needs repair or recalibration.

In-plant evaluation is one part of a program to keep SNM monitors in proper operating condition. Every monitor in a facility is evaluated. In the routine operational form, nuisance-alarm records for each monitor are examined, and each monitor's detection sensitivity is verified; see App. A for information on nuisance-alarm testing. The evaluation takes place without pretesting, recalibration, or other activity that might not simulate the normal use of the monitor. In the post-calibration form, the monitor's detection sensitivity is verified following monitor recalibration. In this case, the monitor is likely to be operating at its best.

\section{METHOD AND GOALS}

The in-plant evaluation is a way to estimate whether an acceptable level of performance for detecting chosen quantities of SNM is obtained from a monitor in routine service or after repair or calibration. The evaluation verifies acceptable performance or discloses faults in hardware or calibration using test sources shielded only by normal source encapsulation and, perhaps, intervening pe rtions of the transporting individual's body. Transporting individuals play an important role in the evaluation by reproducing conditions of routine operation.

The evaluation, when applied as a routine-operational evaluation, provides evidence for continued compliance with the performance goals of security plans or regulatory guidance.

\section{MATERIALS AND CRITERIA}

The materials needed for detectionsensitivity evaluation are agreed upon amounts of material as standard SNM, process SNM or alternative test sources. A monitor's detection sensitivity for certain types of SNM

\footnotetext{
* The synopsis is based on two ASTM drafts: the "Standard Guide to In-Plant Performance Evaluation of Automatic Pedestrian SNM Monitors" and the "Standard Guide to Laboratory Evaluatuion of Automatic Pedestrian SNM Monitor Performance."
} 
can be estimated using alternative test sources. A detection sensitivity estimated with standard HEU or low-burnup plutonium test sources demonstrates that a monitor has adequate gamma-ray sensitivity for detecting equal amounts of the more radioactive forms of SNM: ${ }^{233} \mathrm{U}$ and ${ }^{238} \mathrm{Pu}$. A detection sensitivity estimated with standard $\mathrm{HEU}$ or ${ }^{133} \mathrm{Ba}$ test sources demonstrates that a monitor has adequate gamma-ray sensitivity for detecting low-burnup plutonium in the amounts listed in Table D-I. The information on test source size in Table D-I applies to monitoring situations that require detecting small quantities of SNM. In other monitoring situations where only large items are protected, test sources much larger than the vaiues in the table may be required.

A detection sensitivity estimated for neutron monitors using ${ }^{252} \mathrm{Cf}$ (a spontaneousfission neutron source) can demonstrate adequate neutron sensitivity for detecting lowburnup plutonium in an amount corresponding to $1 \mathrm{~g}$ of ${ }^{240} \mathrm{Pu}$ for each 1000 neutrons/s from ${ }^{252} \mathrm{Cf}$.

\section{PROCEDURES}

Procedures for detection sensitivity evaluation use a preselected test source and a method for an individual to carry the source through the monitor. The specified method takes into account the region of the portal that the source will pass through and the passage speed of the source. The source may have to be attached to an individual to make it move in a desired manner through the monitor. The total number of passages must be chosen, refined by experience, and used thereafter. The number may be different for individual monitors in a plant.

The individuals who will pass the test source through the monitor should first pass through without a source for the chosen number of times. Make a written record of results (passage number, detect or miss) as they are obtained. The testing individuals next pass through transporting a test source. Make a written record of results (passage number, detect or miss) as they are obtained.

\begin{tabular}{|l|l|l|l|l|l|}
\hline \multicolumn{2}{|l|}{ Table D-I. Alternative Test Source Equivalent Amounts } \\
\hline $\begin{array}{l}\text { Monitor } \\
\text { Category }\end{array}$ & $\begin{array}{l}\text { Monitor } \\
\text { Description }\end{array}$ & Plutonium (g) & $\begin{array}{l}\text { Uranium } \\
(\mathrm{g})\end{array}$ & $\begin{array}{l}\text { NaI(T1) } \\
\text { Scintillator } \\
\text { Monitors }\end{array}$ & $\begin{array}{l}\text { Plastic } \\
\text { Scintillator } \\
\text { Monitors }\end{array}$ \\
\hline I & $\begin{array}{l}\text { Standard } \\
\text { plutonium }\end{array}$ & 1 & 64 & 2.5 & 3.2 \\
\hline II & $\begin{array}{l}\text { Standard } \\
\text { uranium }\end{array}$ & 0.29 & 10 & 0.9 & 1.4 \\
\hline III & $\begin{array}{l}\text { Improved } \\
\text { sensitivity }\end{array}$ & 0.08 & 3 & 0.4 & 0.6 \\
\hline IV & High sensitivity & 0.03 & 1 & 0.2 & 0.3 \\
\hline
\end{tabular}




\begin{tabular}{|l|l|l|}
\hline $\begin{array}{l}\text { Table D-II. Number of Detections for Acceptance and Rejection } \\
\text { Tutal Number of } \\
\text { Trials }\end{array}$ & $\begin{array}{l}\text { Number of } \\
\text { Detections for } \\
\text { Acceptance }\end{array}$ & Number of Detections for Rejection \\
\hline 5 & 5 & 4 or less \\
\hline 10 & 9 or more & 8 or less \\
\hline 15 & 12 or more & 11 or less \\
\hline 20 & 15 or more & 14 or less \\
\hline 30 & 20 or more & 19 or less \\
\hline $\begin{array}{l}\text { NOTE: The chosen number of trials must have been completed, and the criteria for that number } \\
\text { of trials must be used tc determine acceptance or rejection of the monitor's performance. }\end{array}$
\end{tabular}

\section{ANALYSIS}

Evaluation results should be tallied as total passages and total $d$-tections. When the total number of passages has been completed and the results tallied, acceptance or rejection of the hypothesis that the monitor is operating properly can be determined from Table D-II.

The acceptance criteria were chosen to provide $95 \%$ confidence that the probability of detection is at least $50 \%$. Results falling at or below the rejection number do not provide $95 \%$ confidence that the probability of detection is at least $50 \%$. In this case, the monitor can be repaired, recalibrated, and evaluated again. In any case, record the results.

\section{REPORTS}

Written reports of in-plant evaluation results serve as evidence for carrying out a scheduled maintenunce and evaluation program. Written reports also document the performance of a particular monitor operating in a particular environment and, in the furure, may provide information that helps to resolve operating problems at that location. 

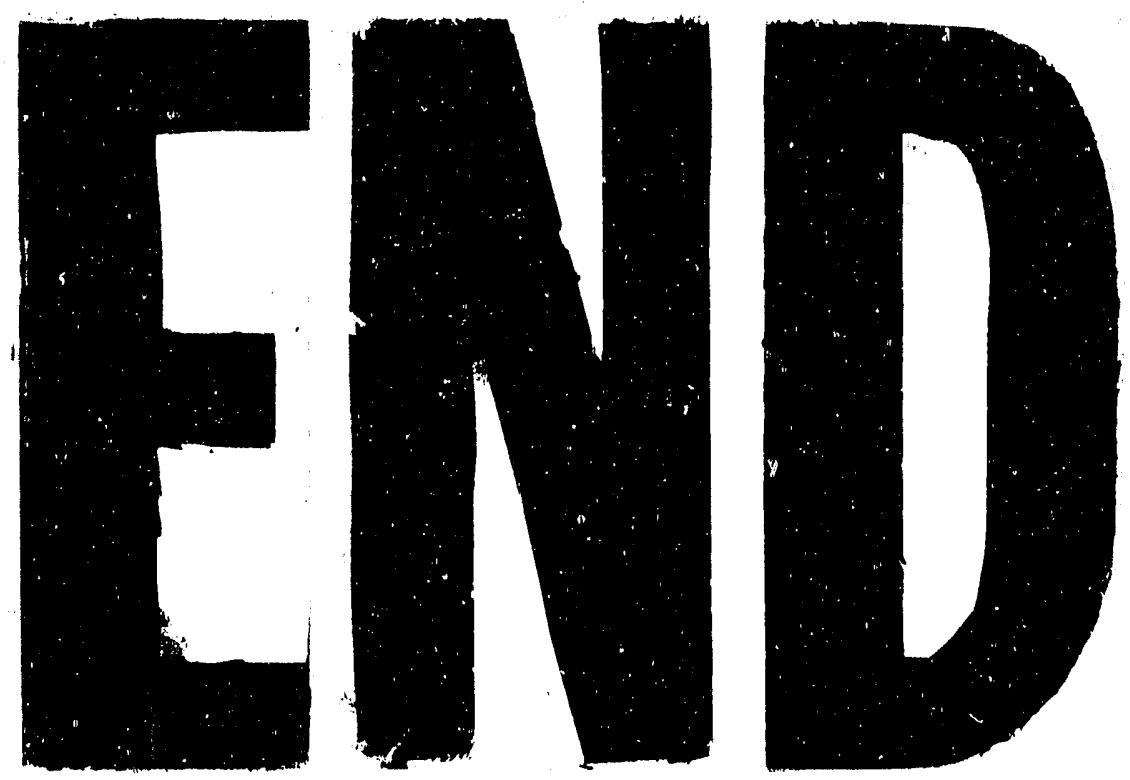

4
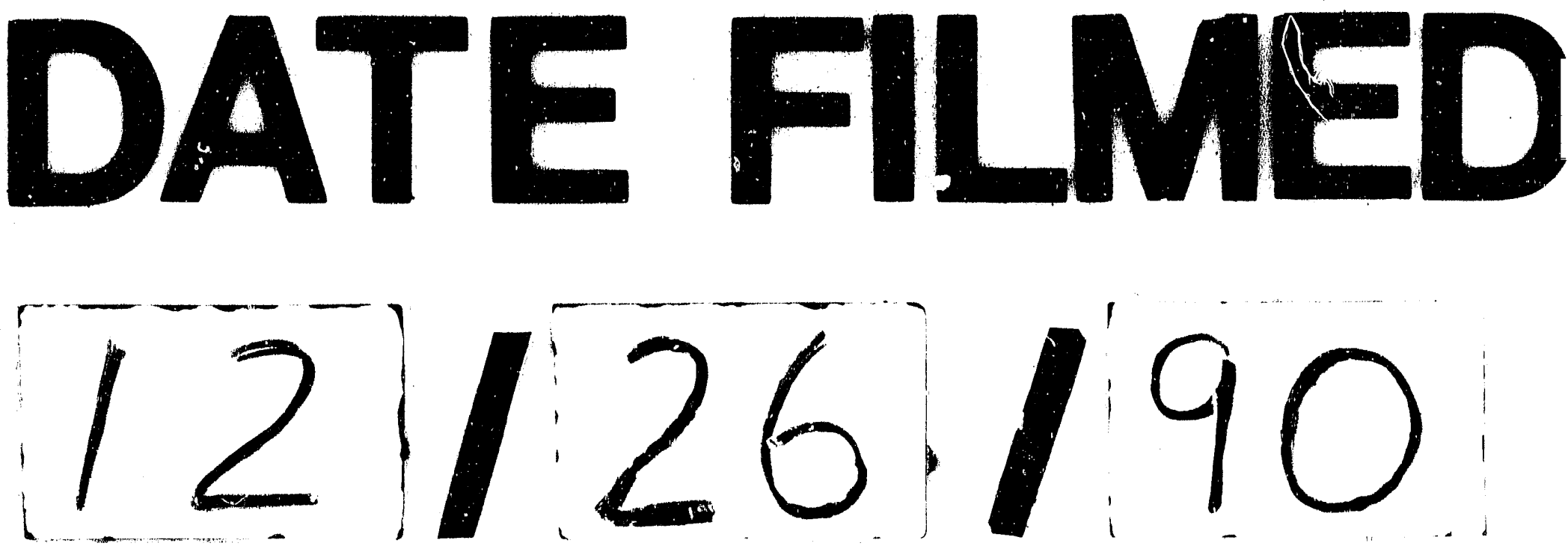
